\title{
Regional oxygen reduction and denitrification rates in groundwater from multi-model residence time distributions, San Joaquin Valley, USA
}

Christopher T. Green ${ }^{1}$, Bryant C. Jurgens ${ }^{2}$, Yong Zhang ${ }^{3}$, J. Jeffrey Starn ${ }^{4}$, Michael J. Singleton ${ }^{5}$, and Bradley K. Esser

${ }^{1}$ corresponding author, U.S. Geological Survey, Menlo Park, California, USA, ctgreen@usgs.gov.

${ }^{2}$ U.S. Geological Survey, Sacramento, California, USA.

${ }^{3}$ University of Alabama Tuscaloosa, Alabama, USA.

${ }^{4}$ U.S. Geological Survey, East Hartford, Connecticut, USA.

${ }^{5}$ Nuclear and Chemical Sciences Division, Lawrence Livermore National Laboratory, Livermore, California, USA

$\underline{\text { keywords }}$

oxygen reduction; denitrification; groundwater; residence time; multi-model analysis; regional water quality 


\begin{abstract}
Rates of oxygen and nitrate reduction are key factors in determining the chemical evolution of groundwater. Little is known about how these rates vary and covary in regional groundwater settings, as few studies have focused on regional datasets with multiple tracers and methods of analysis that account for effects of mixed residence times on apparent reaction rates. This study provides insight into the characteristics of residence times and rates of $\mathrm{O}_{2}$ reduction and denitrification $\left(\mathrm{NO}_{3}{ }^{-}\right.$reduction) by comparing reaction rates using multi-model analytical residence time distributions (RTDs) applied to a data set of atmospheric tracers of groundwater age and geochemical data from 141 well samples in the Central Eastern San Joaquin Valley, CA. The RTD approach accounts for mixtures of residence times in a single sample to provide estimates of in-situ rates. Tracers included $\mathrm{SF}_{6}, \mathrm{CFCs},{ }^{3} \mathrm{H}, \mathrm{He}$ from ${ }^{3} \mathrm{H}$ (tritiogenic $\mathrm{He}$ ), ${ }^{14} \mathrm{C}$, and terrigenic He. Parameter estimation and multi-model averaging were used to establish RTDs with lower error variances than those produced by individual RTD models. The set of multimodel RTDs was used in combination with $\mathrm{NO}_{3}{ }^{-}$and dissolved gas data to estimate zero order and first order rates of $\mathrm{O}_{2}$ reduction and denitrification. Results indicated that $\mathrm{O}_{2}$ reduction and denitrification rates followed approximately log-normal distributions. Rates of $\mathrm{O}_{2}$ and $\mathrm{NO}_{3}{ }^{-}$ reduction were correlated and, on an electron milliequivalent basis, denitrification rates tended to exceed $\mathrm{O}_{2}$ reduction rates. Estimated historical $\mathrm{NO}_{3}{ }^{-}$trends were similar to historical measurements. Results show that the multi-model approach can improve estimation of age distributions, and that relatively easily measured $\mathrm{O}_{2}$ rates can provide information about trends in denitrification rates, which are more difficult to estimate.
\end{abstract}




\section{Introduction}

Reactions of $\mathrm{NO}_{3}{ }^{-}$and $\mathrm{O}_{2}$ are critical factors affecting water quality and geochemical processes in groundwater (NRC, 2000). Denitrification and oxygen reduction are closely linked and are primary reactions affecting variations of redox chemistry in shallow groundwater (e.g., Vogel et al., 1981; Mariotti et al., 1988; Böttcher et al., 1990; Smith et al., 1991; Mengis et al., 1999; Böhlke et al., 2002; Groffman et al., 2006; Rivett et al., 2008; Green et al., 2008b; McMahon et al., 2008; Green et al., 2010; Liao et al., 2012). The processes directly affect concentrations of $\mathrm{NO}_{3}{ }^{-}$, with broad implications for human and environmental health (Hallberg, 1986; Burt et al., 1993; Fan and Steinberg, 1996; Böhlke, 2002; Hatfield and Follett, 2008; Dubrovsky et al., 2010). In addition, the presence of high nitrate concentrations typically indicates the zone of influence of modern agricultural or waste water that can carry other anthropogenic contaminants and can affect the mobility of in-situ contaminants such as uranium and arsenic (Smedley and Kinniburgh, 2002; Jurgens et al., 2010). Rigorous characterization of the fate and transport of $\mathrm{NO}_{3}{ }^{-}$and $\mathrm{O}_{2}$ is therefore essential to managing a range of water quality issues.

Much of the current understanding of oxygen reduction and denitrification in aquifers stems from local studies involving analysis of groundwater samples. After recharge, aqueous concentrations of $\mathrm{O}_{2}$ typically decrease via microbially mediated reactions with electron donors such as organic carbon or reduced iron or sulfur compounds. After $\mathrm{O}_{2}$ is depleted, $\mathrm{NO}_{3}{ }^{-}$ undergoes a series of denitrification reactions with electron donors that ultimately produce $\mathrm{N}_{2}$. This pattern of reactivity has been observed in local-scale in-situ reactors (Korom et al., 2005) and in flowpath studies of well transects, typically at scales of a few km or less (e.g. Böhlke and Denver, 1995; Singleton et al., 2007; Tesoriero et al. 2007; Green et al., 2008b; McMahon et al. 
2008; Welch et al., 2011; Young et al., 2013) that use tracers of chemistry (such as dissolved $\mathrm{N}_{2}$ ), recharge conditions (noble gases) and residence time (atmospheric tracers). Challenges remain to connect the findings of local-scale studies to regional observations that are key to understanding the importance of $\mathrm{O}_{2}$ reduction and denitrification for regional water quality (Otero et al. 2009; Menció et al., 2011; Landon et al., 2011; Refsgaard et al., 2014) and for synthesis across landscapes (Seitzinger et al., 2006).

Recent studies have compared results of local studies towards the goal of identifying common features of nitrate and oxygen reactivity (Tesoriero and Puckett, 2011; Liao et al, 2012). Because solid phase electron donors from lithologic sources tend to limit reaction rates (Green and Bekins, 2010; Tesoriero and Puckett, 2011), the reaction kinetics, especially as regulated by concentrations of $\mathrm{O}_{2}$ and $\mathrm{NO}_{3}{ }^{-}$, are not well known. Zero or first order formulations have been commonly used for simple rate estimates, in lieu of evidence for the applicability of more complex kinetic models. Tesoriero and Puckett (2011) analyzed $\mathrm{O}_{2}$ and $\mathrm{NO}_{3}{ }^{-}$reduction rates at 12 sites across the USA using apparent ages (assuming piston flow) from tracer concentrations to estimate zero order and first order rates of $\mathrm{O}_{2}$ reduction and denitrification. They found that reaction rates varied over orders of magnitude among sites. Liao et al. (2012) analyzed tracers at 14 sites across the USA using a vertical flux model with a simplified representation of unsaturated and saturated hydrology. They found that zero order $\mathrm{O}_{2}$ and $\mathrm{NO}_{3}{ }^{-}$reaction rates tended to correlate, and that reaction rates were a key factor in determining the eventual steadystate depth of the nitrate fronts. These previous comparisons of local-scale studies indicate that $\mathrm{O}_{2}$ and $\mathrm{NO}_{3}{ }^{-}$reduction rates may be related, but no studies to our knowledge have quantified and compared $\mathrm{O}_{2}$ and $\mathrm{NO}_{3}{ }^{-}$reaction rates in a residence time distribution (RTD) framework for a large agricultural region. One of the goals of this study is to fill this knowledge gap. 
Mixing of residence times in groundwater samples poses a challenge for regional characterization of $\mathrm{O}_{2}$ reduction and denitrification rates. Regional studies typically rely on existing water supply wells with long screens that may produce waters with broad mixtures of residence times from different depths (Landon et al., 2010b). In addition to effects of well construction, geological heterogeneity creates mixed samples even in short screened monitoring wells. Green et al. (2010) found that such mixing of residence times can cause apparent rates derived from groundwater samples to differ from actual local rates by an order of magnitude or more. Improving the accuracy of rate estimates therefore requires methods that account for ranges of residence times and reaction times in a single sample.

A common approach to estimate RTDs in groundwater samples is to apply analytical RTD (also known as "lumped parameter") models. Numerous mathematical forms of the RTD solutions are available (Maloszweski and Zuber, 1982; Visser et al., 2013; Green et al., 2014; Marçais et al., 2015). Comparisons of numerical test cases to various analytical solutions, however, indicate that it can be difficult to determine the form of the RTD a-priori from well construction and aquifer information (Green et al., 2014). It may be advantageous, therefore to consider a range of forms of the RTD in analyzing tracer data along with methods such as multimodel averaging. Consideration of multiple conceptual models of aquifers can minimize bias in predictions (e.g., Troldborg et al., 2007; Rojas et al., 2010). Efforts are ongoing to evaluate the ability of various model-averaging approaches to improve groundwater-model structural adequacy and to reduce prediction errors (e.g., Diks and Vrugt, 2010; Rojas et al., 2010; Ye et al., 2010; Seifert et al., 2012; Refsgaard et al., 2012; Foglia et al., 2013). Use of multi-model averaging has not been explored, to our knowledge, in the use of RTD models calibrated to tracer 
data. In this study we implement methods of analysis that involve multiple possible RTDs and we test multi-model averaging as an approach for generating RTDs.

The main objective of this work is to test the hypothesis that denitrification rates relate to $\mathrm{O}_{2}$ reduction rates in a regional context. We estimated rates of reactions of $\mathrm{O}_{2}$ reduction and denitrification using a multi-model RTD framework applied to a regional dataset of tracers from the Central Valley, California. Multi-model approaches were tested and applied to reduce errors in estimated RTDs. Automatic parameter estimation techniques were used to determine the most likely values and uncertainties of rate parameter estimates. Rates were summarized in composite distributions based on estimated values and uncertainties, and were compared between $\mathrm{O}_{2}$ and $\mathrm{NO}_{3}{ }^{-}$reduction. The final $\mathrm{RTD}$ and reaction models were used to estimate trends in historical $\mathrm{NO}_{3}{ }^{-}$concentrations and were compared to observations. The results indicate that the multimodel RTD approach provides a robust and computationally efficient method for estimating $\mathrm{NO}_{3}{ }^{-}$reactivity and trends in a regional context.

\section{Materials and methods}

The procedures to estimate residence time distributions and reaction parameters are shown in Figure 1. For each groundwater sample, four RTD models were calibrated to the age

tracer concentrations (tritium, ${ }^{3} \mathrm{H}$; tritiogenic helium, ${ }^{3} \mathrm{He}_{\text {trit }}$; terrigenic helium-4, ${ }^{4} \mathrm{He}_{\text {terr }}$; carbon$14,{ }^{14} \mathrm{C}$; chlorofluorocarbons, CFC-11, CFC-12, and CFC-113; and sulfur hexafluoride, $\mathrm{SF}_{6}$ ). The four predicted RTDs for each well sample were then combined into a single multi-model RTD using multi-model averaging techniques. To estimate input histories of $\mathrm{NO}_{3}{ }^{-}$, and oxygen reduction and denitrification reaction parameters, each multi-model RTD was combined with input function of $\mathrm{NO}_{3}{ }^{-}$and $\mathrm{O}_{2}$, and the resulting mathematical model was calibrated to observed 
concentrations of $\mathrm{O}_{2}, \mathrm{NO}_{3}{ }^{-}$, and $\mathrm{N}_{2, \mathrm{D}}$. This approach builds on existing techniques for use of residence time distribution functions to analyze water quality. Green et al. (2014) applied the same four RTD models to a synthetic dataset from a numerical model in this study area to estimate conservative tracer concentrations. This study adds multi-model averaging techniques and reactive parameter estimation for actual tracer data from 141 well samples. These methods are described in five sections devoted to site descriptions (section 2.1), tracer sampling and data processing (section 2.2), residence time distribution models (section 2.3), multi-model averaging procedures (section 2.4), and calibration approach (section 2.5).

\subsection{Study site description}

The US Geological Survey (USGS) National Water Quality Assessment (NAWQA) program has undertaken projects to characterize and forecast water quality, including nitrate concentrations, across large contiguous regions of the USA. The NAWQA program and the State of California Groundwater Ambient Monitoring and Assessment (GAMA) program have developed studies in the Central Valley California, a region of substantial economic importance and with a diversity of crop types and geochemical settings. The current study site consists of an approximately $50 \mathrm{~km}$ by $100 \mathrm{~km}$ area in the Central Eastern San Joaquin Valley, California (Figure 1). Land uses are mainly agricultural with some urban development. In the semi-arid climate of the Central Valley, agricultural productivity depends on irrigation, with deliveries in the study area coming primarily from surface water diversions and supplemented with groundwater pumping (Phillips et al., 2007). The aquifer materials at the study site consist of interlayered fine- and coarse-grained sediments of alluvial fan deposits originating in the eastern 
Sierras and terminating in finer grained basin deposits near the axis of the valley. Groundwater flow is generally from northeast to southwest (Landon et al., 2011).

Previous studies in the central-eastern San Joaquin Valley indicate variable geochemical conditions. Detailed local studies have identified gradual denitrification (Green et al., 2008b; Green et al., 2010; Liao et al., 2012) as well as relatively conservative movement of $\mathrm{NO}_{3}{ }^{-}$ (Jurgens et al., 2008). In a regional study, Landon et al. (2011) classified 73\% of groundwater samples as oxic $\left(\mathrm{O}_{2}\right.$ greater than $\left.0.5 \mathrm{mg} \mathrm{L}^{-1}\right)$. The remaining low- $\mathrm{O}_{2}$ samples tended to be associated with long residence times at depth or in discharge areas near the valley trough, although maps of groundwater redox conditions showed considerable local spatial variability (Figure 2, Landon et al., 2011).

\subsection{Tracer sampling and analysis}

Tracer data were collected from 141 groundwater well samples as a part of the California GAMA program (75 wells samples, Landon and Belitz, 2008; and Landon et al., 2010a), NAWQA program (27 wells, see Jurgens et al., 2008), and a joint US Geological Survey / California State Water Resources Control Board study of aquifer vulnerability to contamination in Modesto (CAS, 39 well samples, Wright et al., 2004). The dataset included 141 well samples with one or more age-tracer concentrations and 129 well samples with three or more age-tracer concentrations (Figure 1, Supporting Information Table S1). The full dataset was used to estimate errors in age-tracer concentration observations for determination of weights (Section 2.3) and RTDs were estimated for the dataset of well samples with three or more age-tracer

concentrations. Age-tracers included ${ }^{3} \mathrm{H}$ ( $\mathrm{n}=140$ samples), tritiogenic helium $\left({ }^{3} \mathrm{He}_{\text {trit }}, \mathrm{n}=130\right)$, terrigenic helium-4 $\left({ }^{4} \mathrm{He}_{\text {terr }}, \mathrm{n}=130\right),{ }^{14} \mathrm{C}(\mathrm{n}=46), \mathrm{CFC}-11(\mathrm{n}=11), \mathrm{CFC}-12(\mathrm{n}=7), \mathrm{CFC}-113$ 
$(n=10)$, and $\mathrm{SF}_{6}(\mathrm{n}=13)$. Tritiogenic helium produced by the radioactive decay of ${ }^{3} \mathrm{H}$ is often used in conjunction with ${ }^{3} \mathrm{H}$ concentration and ${ }^{3} \mathrm{H}$ decay rate to estimate a single "apparent age", but in this study is an independent, forward-modeled tracer. Details of sample collection procedures and data processing are in the Supporting Information.

\subsection{Concentration estimates from analytical residence time distribution models}

The application of RTDs to estimate tracer concentrations follows the procedures of Green et al. (2014), which evaluated prediction errors of RTDs. Tracer concentrations can be estimated using a convolution equation

$$
C_{s, i}(t)=\int_{-\infty}^{t}\left[C_{0, i}\left(t^{\prime}\right)-R_{i}\left(t-t^{*}\right)\right] g\left(t-t^{\prime}\right) d t^{\prime},
$$

where $C_{s, i}$ is the concentration of tracer, $i$, in the sample at time $t ; C_{0, i}$ is the input concentration, for example of an atmospheric tracer arriving at the water table at the time of recharge, $t^{\prime} ; R_{i}$ is the mass lost to (or gained from) reactions as a function of the time interval between the time, $t^{*}$, at the start of the reaction, and the time of sampling $t$; and $g$ is a reference RTD (sometimes also referred to as a "memory kernel", "response function", or "Green's function") describing output of a conservative tracer injected instantaneously at the inlet. For simplicity, the term $t$ - $t$ ' can be replaced with $\tau$, which is the time of travel between input and sampling, and $t-t^{*}$ can be replaced with $\tau^{*}$, the reaction time. Other studies have used similar approaches to link tracer concentrations with age distributions (Browne and Guldan, 2005; Osenbrück et al., 2006; Kennedy et al., 2009; Starn et al., 2014; Massoudieh et al., 2013; McCallum et al., 2014, Alikhani et al., 2016). 
The function $R$ depends on the choice of reaction kinetics and the tracer of interest. First order and zero order kinetic reaction parameters were estimated in this study to allow comparison with previous studies of these reactions in aquifers. Following the form of Eq. (1), first order kinetics are $R_{i}=C_{0, i}-C_{0, i} \exp \left(-\lambda_{i} \tau^{*}\right)$, where $\lambda_{i}$ is the first order reaction rate coefficient. Zero order kinetics are $R_{i}=k_{i} \tau^{*}$, where $k_{i}$ is the zero order reaction rate coefficient. For oxygen and nitrate, two separate sets of calculations were completed with both solutes undergoing either first order or zero order decay. For the production of excess $\mathrm{N}_{2}$ from denitrification $\left(\mathrm{N}_{2, \mathrm{D}}\right)$ the reaction rate is equal to $-R_{N}$, the negative of the $\mathrm{NO}_{3}{ }^{-}$rate of consumption by denitrification. The reaction rate coefficients for $\mathrm{O}_{2}$ and $\mathrm{NO}_{3}{ }^{-}$were calibrated as described in Section 2.5. For ${ }^{4} \mathrm{He}_{\text {terr }}$, an apparent zero order release rate of ${ }^{4} \mathrm{He}_{\text {terr }}$ of $156 \mu \mathrm{cm}^{-3} \mathrm{~m}^{-3} \mathrm{yr}^{-1}$ was estimated based on preliminary calibrations to minimize the residuals between the observed and estimated ${ }^{4} \mathrm{He}_{\text {terr. }}$. The estimated apparent release rate is in the range of 130 to $230 \mu \mathrm{cm}^{3} \mathrm{~m}^{-3} \mathrm{yr}^{-1}$ reported at four other shallow aquifers (Solomon et al., 1996). The reaction kinetics were first order for all other atmospheric tracers, with $\lambda$ equal to $0.056 \mathrm{yr}^{-1}$ for ${ }^{3} \mathrm{H}, 0.00012 \mathrm{yr}^{-1}$ for ${ }^{14} \mathrm{C}$, and 0 for $\mathrm{CFC}$ 's and $\mathrm{SF}_{6}$. For all tracers except $\mathrm{NO}_{3}{ }^{-}$, the reaction time length $\tau^{*}$ is equal to the time below the water table, $\tau$. For $\mathrm{NO}_{3}{ }^{-}$, the reaction time is shortened by an amount $\tau_{\text {lag }}=\tau-\tau^{*}$ as a result of inhibition of denitrification by $\mathrm{O}_{2}$. The time-lag in denitrification is estimated as $\tau_{\mathrm{lag}}=\left(\mathrm{O}_{2,0}-\mathrm{O}_{2, \text { cut }}\right) / k_{O}$ for zero order kinetics or $\tau_{\mathrm{lag}}=\ln \left(\mathrm{O}_{2,0} / \mathrm{O}_{2, \text { cut }}\right) / \lambda_{O}$ for first order kinetics, where $\mathrm{O}_{2,0}$ is the initial concentration of $\mathrm{O}_{2}$ and $\mathrm{O}_{2 \text {,cut }}$ is an oxygen cutoff concentration at which denitrification begins, set equal to $1 \mathrm{mg} / \mathrm{L}$ based on previous studies of local-scale reactivity in the study area (Green et al., 2010).

Input functions, $C_{0, i}\left(t^{\prime}\right)$, at the water table were estimated as follows. Pre $1950{ }^{14} \mathrm{C}$ inputs were from Reimer et al. (2009). For years after 1950, the ${ }^{14} \mathrm{C}$ input function was from Levin and 
Kromer (2004) and Levin et al. (2008). Input concentrations of CFC-12 and $\mathrm{SF}_{6}$ gases were assigned on the basis of equilibrium partial pressures with chronologies of atmospheric concentrations assumed to be in equilibrium with unsaturated zone air overlying the water table (Busenberg and Plummer, 1992; 2008). Input of ${ }^{3} \mathrm{H}$ was from estimates of ${ }^{3} \mathrm{H}$ in precipitation compiled for the United States (Michel, 1989) with a five-year running average as a first-order approximation of unsaturated zone dispersion, and with a two year travel time in the unsaturated zone, as observed at an unsaturated zone study site near the center of the current study area (Fisher and Healy, 2008; Green et al., 2008a). Inputs of ${ }^{4} \mathrm{He}_{\text {terr }}$ and $\mathrm{N}_{2, \mathrm{D}}$ at the water table were zero at all times. Input of $\mathrm{O}_{2}$ was $9.4 \mathrm{mg} / \mathrm{L}$ at all times based on air-saturated water at 1008 mbar atmospheric pressure and 18 degrees $\mathrm{C}$.

The input function of $\mathrm{NO}_{3}{ }^{-}$was estimated using well samples with estimates of $\mathrm{NO}_{3}{ }^{-}$and $\mathrm{N}_{2, \mathrm{D}}$. There were 52 well samples with concentrations of both tracers. The original $\mathrm{NO}_{3}{ }^{-}-\mathrm{N}$ concentration associated with the water sample before denitrification $\left(\mathrm{NO}_{3}{ }^{-} \mathrm{N}_{0}\right)$ was estimated as the sum of $\mathrm{NO}_{3}{ }^{-}-\mathrm{N}$ and $\mathrm{N}_{2, \mathrm{D}}$. A single "shape function" was estimated for the entire study area to represent the overall temporal trends of historic $\mathrm{NO}_{3}{ }^{-} \mathrm{N}$ concentration in recharge. The shape function, $C_{0, N}^{*}\left(t^{\prime}\right)$, was constructed by linear interpolation between calibrated concentration values at 5 year intervals from 2005 to 1950, 10 year intervals from 1950 to 1900, and 50 year intervals from 1850 to 1700 . The shape function concentrations were estimated by calibrating to the full set of $\mathrm{NO}_{3}{ }^{-}-\mathrm{N}_{0}$ observations (see Section 2.5), similar to the approach used previously in a portion of this study area (Green et al., 2010). Each well-specific input function, $C_{0, N}\left(t^{\prime}\right)$ was estimated by multiplying $C_{0, N}^{*}\left(t^{\prime}\right)$, by a linear scaling factor to give a match between the modeled and estimated concentration of $\mathrm{NO}_{3}{ }^{-}-\mathrm{N}_{0}$ at that well. Examples of the linearly scaled shape function are presented in Section 3.3. 
For $g(\tau)$ in the convolution Eq. (1), this study uses the same four RTD models that were evaluated in Green et al. (2014) with synthetic data from subregions of the study area (Table 1). The scaled-dispersion model (SDM) was developed by Green et al. (2014) to simulate heavytailed RTDs based on simplified geometry of flow to a well screen from recharge points on the water table (Table 1). Heavy tails often occur in RTDs as indicated by numerical models with detailed geological heterogeneity (Zhang et al., 2013, Green et al., 2014), inversion of multiple mass exchange rates (Haggerty et al., 2000), and theoretical studies of groundwater transport in heterogeneous systems (Berkowitz et al., 2006; Neuman and Tartakovsky, 2009; Zhang et al., 2007; Engdahl et al., 2012). For multimodal distributions stemming from geological heterogeneity (Green et al., 2010; 2014) or well construction (Landon et al., 2010b), a dual exponential piston model (DEPM) was applied (multimodal RTDs were generated also via averaging of multiple RTD models as described in section 2.4). Two monomodal, light-tailed RTD models were applied, including the exponential piston model (EPM) and the advectiondispersion model (DM).

Each RTD model used two adjustable parameters for calibration (Section 2.5). For the EPM distribution, $T$ and $\eta$ were calibrated (Table 1). For the DEPM distribution, the values of $\eta_{1}$ and $\eta_{2}$ were fixed at 1.5 and $f_{1}$ was fixed at 0.5 based on manual adjustments in preliminary trials. The values of $T_{1}$ and $T_{2}$ were calibrated for $\mathrm{EPM}_{1}$ and $\mathrm{EPM}_{2}$ respectively. For the DM distribution, the value of $x$ was fixed at the depth of the center of the well screen below the water table, and $D_{x}$ and $v$ were calibrated. For the SDM, the factor A (controlling the longitudinal dispersion; see Table 1) was fixed at 0.5 and the factor $\mathrm{C}$ (controlling anisotropic dispersion) was fixed at 1000, as implemented in Green et al. (2014), The value of $v_{h}$ was fixed at $30 \mathrm{~m} \mathrm{yr}^{-1}$ based on numerical model estimates for the study area (Phillips et al., 2007). The variable $y_{w}$ was 
set equal to the depth of the center of each well screen below the water table. Parameters $v_{v}$ and $B$ were calibrated.

\subsection{Multi-model averaging}

Several multi-model averaging approaches are available, ranging in complexity from a simple arithmetic average to more sophisticated methods based on goodness-of-fit and observation sensitivities (Seifert et al., 2012). To evaluate the efficacy of model averaging techniques applied to RTD models, we tested six model-averaging procedures (Table 2) applied to the synthetic dataset of RTDs and tracer concentrations from Green et al. (2014) which were from a heterogeneous numerical model of flow and transport in a sub-region of the study area and used the same RTD models as the current study. For each of the 84 synthetic RTDs, the four RTD models discussed in section 2.3 were averaged using the six multi-model approaches, and the estimated values of the median age of the $\mathrm{RTD}$ and $\mathrm{NO}_{3}{ }^{-}$concentrations were compared to the actual (synthetic) values to evaluate errors.

The six model averaging approaches in this study included equal weights averaging (EWA), Granger-Ramanathan averaging with negative and positive weights (GRAneg) or only positive weights (GRA), Akaike information criterion selection (AIC-S) or weights (AIC), and Kashyap information criterion weights (KIC) (Table 2). For each multi-model method, RTD predictions were based on weighted averages (e.g., Poeter and Anderson, 2005),

$$
p_{m m}=\sum_{j=1}^{m j} w_{j}\left(p_{j}\right),
$$

where $p_{m m}$ is the multi-model predicted RTD, $w_{j}$ is the weight assigned to model $j$ of $m_{j}$ models, and $p_{j}$ is the predicted RTD of model $j$. Multi-model predictions of $\mathrm{NO}_{3}{ }^{-}$were calculated based 
on applying the multi-model RTD as $g(\tau)$ in Eq. (1). The two Granger-Ramanathan scenarios allow negative weights, $w_{j, G R A}$ (GRAneg) or only positive averaging weights $w_{j, G R A}>0(\mathrm{GRA})$. The Akaike information criteria scenarios use standard AIC weights (AIC) or a selection scenario (AIC-S) in which the model with the lowest AIC value was selected, i.e., assigned $w_{\mathrm{j}}=1$ while all the other models were assigned $w_{\mathrm{j}}=0$. The AIC-S scenario is equivalent to selecting the model with the minimum sum of weighted squared errors (Eq. (3)). For the 2-parameter 5observation models in the synthetic dataset, the AIC weights are equal to those estimated using AICc or Bayesian information criterion (BIC) (Poeter and Hill, 2007).

\subsection{Calibration}

The RTD model parameters and reaction parameters were calibrated using PEST (Doherty, 2008), a numerical code for nonlinear parameter estimation. The approach minimizes the weighted difference between the observations (e.g., synthetic or actual age-tracer concentrations) and simulated equivalent values (e.g., analytical RTD estimates of age-tracer concentrations),

$$
\Phi(\mathbf{b})=\sum_{i=1}^{m i} \omega^{2}{ }_{i}\left(y_{i}-y_{i}^{\prime}\right)^{2}
$$

where $\Phi(\mathbf{b})$ is the objective function based on the vector $(\mathbf{b})$ of $m p$ parameters, $y_{i}$ is an observation, $y_{i}{ }^{\prime}$ is a simulated equivalent, $\omega_{i}$ is an observation weight equal to the inverse of the error (standard deviation) for that observation, and $m_{i}$ is the number of observations (Hill and Tiedeman, 2007, Eq. 3.1a). All RTD models had two calibrated parameters, including $T$ and $\eta$ for the EPM, $T_{1}$ and $T_{2}$ for the DEPM, $D_{x}$ and $v$ for the DM, and $v_{v}$ and $B$ for the SDM, as described in Section 2.3. 
The observation weights used in this study correspond to the "Error II" scenario as described in Green et al. (2014), based on analysis of duplicate samples from this dataset and other data from the study area (Green et al., 2008b; Green et al., 2010). A summary is provided below. For $\mathrm{SF}_{6}$, the standard deviation of each sample was estimated as $6.1 \%$ of the concentration plus 0.26 parts per trillion by volume (pptv). For ${ }^{14} \mathrm{C}$, standard deviations were estimated as $0.018 \%$ of the concentration plus 10 percent modern carbon (pmc). Coefficients of variation were assigned as $28 \%$ for $\mathrm{CFC}-11,39 \%$ for $\mathrm{CFC}-12$, and $35 \%$ for $\mathrm{CFC}-113$. Because of the relatively high uncertainty of assigning a spatially and temporally uniform rate of generation, ${ }^{4} \mathrm{He}_{\text {terr }}$ observations were assigned a coefficient of variation of $100 \%$, down to a minimum standard deviation of $100 \times 10^{-9} \mathrm{~cm}^{3} \mathrm{~g}^{-1}$ of water at standard temperature and pressure $\left(\mathrm{cm}^{3}\right.$ STP $\left.\mathrm{g}^{-1}\right)$. For ${ }^{3} \mathrm{He}_{\text {trit }}$, errors were calculated for each sample using a combination of linear error propagation for forward calculations and nonlinear simultaneous error estimation as implemented, for example, in Welch et al. (2011) applied to the inverse model of AeschbachHertig et al. (1999) for estimating recharge temperature and excess air. The majority of error in ${ }^{3} \mathrm{He}_{\text {trit }}$ observations stemmed from uncertainty in the estimates of terrigenic $\mathrm{He}$. For $\mathrm{NO}_{3}{ }^{-}$and $\mathrm{O}_{2}$, weights were estimated as in Green et al. (2010). For $\mathrm{N}_{2, \mathrm{D}}$, standard deviations were estimated by error propagation in the equations used to estimate $\mathrm{N}_{2, \mathrm{D}}$ concentration.

\section{Results and discussion}

\subsection{Multi-model RTD averages}

Synthetic datasets were used to evaluate various multi-model averaging approaches applied to RTD models. For each of the 84 synthetic well samples from Green et al. (2014), the four RTD models discussed in section 2.3 were calibrated to the synthetic tracer data. The four 
estimated RTDs were then averaged into a single multi-model RTD for each of the six multimodel approaches. The values of the median age and $\mathrm{NO}_{3}{ }^{-}$concentrations from the multi-model RTD were compared to the actual (synthetic) values to evaluate errors.

The comparisons of predicted to actual (synthetic) median residence time and $\mathrm{NO}_{3}{ }^{-}$ concentrations from the six multi-model approaches indicated that differences among the multimodel approaches were moderate (Table 3). The range of median errors for the six multi-model approaches was less than $50 \%$ of the minimum median error of each prediction type. The relative performance of the multi-model approaches depended on the prediction type, e.g. with GRAneg giving the minimum median error for $\mathrm{NO}_{3}{ }^{-}$predictions but the greatest median error for 50 -year $\mathrm{NO}_{3}{ }^{-}$predictions. This is consistent with previous observations that optimal model weights depend on the type of prediction (Refsgaard et al., 2012; Seifert et al., 2012) and the time-period of the observations relative to the predictions (Diks and Vrugt, 2010). For further applications to field data in this study, AIC was selected as an approach that gave relatively low errors across multiple predictions. The AIC method yielded the lowest median error for median age predictions and 50-year $\mathrm{NO}_{3}{ }^{-}$predictions and had moderate errors for $\mathrm{NO}_{3}{ }^{-}$predictions. AIC has compared favorably with other methods in previous applications to model selection (Foglia et al., 2013) and model averaging with small parameter sets (Diks and Vrugt, 2010), and is simple to implement in comparisons of calibrated analytical models (e.g. Green et al., 2015). However, other studies have found KIC to have desirable model selection properties not shared by AIC and other averaging methods (e.g., Ye et al., 2008).

AIC averaging reduced regression error variances (defined below) of RTD models calibrated to the field observations. Figure 3 a shows box plots of the distributions of regression error variance over all wells for the individual RTD models and for the AIC averaged RTD 
models for the field data along with the AIC average for the synthetic dataset. The regression error variance is $\sigma^{2}=\Phi_{0} /\left(m_{i}-m_{p}\right)$, where $\Phi_{0}$ is the minimized objective function from Eq. (3), $m_{i}$ is the number of observations and $m_{p}$ is the number of parameters. If weights accurately reflect the uncertainty of observations and the models adequately represent the structure of the modeled system, the error regression variance will be close to 1 (Hill and Tiedeman, 2007). The median of AIC average error variances for the actual tracers from 129 wells was lower than that of the individual models, was comparable to results for the synthetic dataset, and was close to 1 . The application of AIC substantially reduced the regression error variance of the RTD models as shown by the greater medians and interquartiles of the individual models as compared to the AIC average. Synthetic and field applications of AIC yielded approximately log-normal distributions of error variance with medians near 1. Overall, the regression errors of the AIC averages were not indicative of systematic structural errors and were lower than values often seen in distributed parameter numerical models of reactive transport. For example, reactive transport models in Green et al. (2010) in a portion of this study area had regression error variances of 8 to 17, which are at the extreme high end of the AIC averages of the RTDs applied to observed tracers.

The relative probability estimates of the RTD models illustrate the difficulty of selecting a single model for a dataset, and the potential advantage of applying multiple models. Figure $3 b$ shows the distributions of estimated model probabilities (i.e. AIC weights) for each of the RTD models among the 129 modeled well samples. All the RTD models had appreciable probabilities, with medians ranging from 0.15 (SDM and DEPM) to 0.27 (DM) and with significant overlap among the distributions, highlighting the difficulty in choosing a single model. Examples of the individual RTD models, AIC weighted average, and AIC weights are shown in Figure 4 for well samples 1 and 17. As illustrated by these examples, multiple RTD models often showed 
appreciable (e.g. >0.1) probabilities for each well sample, and no single RTD model consistently yielded the greatest probability among all well samples. Of the 129 well samples with RTD estimates, SDM was the most likely model for 26, DM for 48, DEPM for 31 and EPM for 24. Such variability among wells may result from differences in local hydrogeological features and well construction.

As this is the first multi-model RTD study of its kind, it is difficult to assess the generality of the results. Previous work by Green et al. (2014) with synthetic data indicated that a-priori selection of the optimal form of the RTD model was difficult because of the uncertainty in local geological features; this study yielded the similar result that no single RTD model consistently produced maximum probabilities, and multi-model averaging helped to reduce regression error variance as compared to individual RTD models. Questions remain, however, about the extent to which reduced regression error variance corresponds to lower prediction errors (Marçais et al., 2015). Additional issues for future study of multi-model RTDs include increased complexity relative to use of individual models, the role of direct interpretation of RTD parameters from the physical attributes of the system (e.g. Zhang et al., 2014), and effects of incorporating different forms of RTDs such as discrete distributions (Visser et al., 2013) and gamma distributions (e.g. Marçais et al., 2015).

\subsection{Regional Residence Time Distributions}

The collection of RTDs gives an estimate of aquifer RTD characteristics that is consistent with general knowledge of the hydrologic system in the Central Eastern San Joaquin Valley. Composite RTDs from multiple samples have been estimated for streambeds where sampling is relatively convenient (Browne and Guldan, 2005; Kennedy et al., 2009; Gilmore et al., 2016) but 
have not, to our knowledge, been demonstrated for a regional groundwater system at the scale of the current study. The collection of well samples in this study may provide a first-order approximation of the age distribution of the upper aquifer because the depths of samples are approximately evenly distributed in the upper $80 \mathrm{~m}$, with 24 well samples from depth of center of screen 0-20 m below water table, 31 samples from 20-40 m, 45 samples from 40-60 m, and 29 samples from $>60 \mathrm{~m}$. Figure 5 shows the mean, median, and 20th 99 th percentiles of the collection of multi-model RTDs for all well samples. The mean is the arithmetic average value of $g(\tau)$ among all RTD estimates. For each percentile, $p$, the curve shows the values of $g(\tau)$ below which $p$ percent of RTDs occur. Medians of individual RTDs are also shown as vertical lines at the bottom of the figure. The mean RTD follows an approximately exponential distribution, with the greatest probability of residence time being close to zero and decreasing probability with increasing age. The exponential model (EM) of the residence time distribution of the aquifer is consistent with theory for the sampling of the full depth of an unconfined, regional aquifer (Maloszewski and Zuber, 1982; Cook and Böhlke, 2000; Goderniaux et al., 2013). There are, however, notable characteristics of the RTDs of the well samples in this study that differ from the classical model of an exponential distribution of ages. First, the mean, median, and percentiles of the RTDs consistently show an elevated probability density for residence times in the 30 to 70 year range, which may relate to historical increases in recharge during this time period as well as elevated density of sampling in the 40-60 m depth range. Second, there is power law tailing (straight line on the log-log plot) in the late-time portion of the mean RTD, with the probability for large resident times decreasing more slowly than predicted by the best-fit exponential model. This power-law tail likely results from the effects of regional-scale geological heterogeneity on late-time tails on RTDs (Zhang et al., 2013) that are absent in 
homogeneous models of regional residence times (Goderniaux et al., 2013) and may also relate to extended residence times in deeper groundwater that was replenished in pre-agricultural conditions with lower recharge rates than at the present.

\section{3 $\mathrm{NO}_{3}{ }^{-}$Inputs and Reaction Rates}

The estimated family of $\mathrm{NO}_{3}{ }^{-}$input functions was consistent with the agricultural history of the area (Landon et al., 2011), estimates of regional $\mathrm{N}$ applications, and previous estimates of $\mathrm{N}$ inputs. Input functions of $\mathrm{NO}_{3}{ }^{-}$were determined by calibration as discussed in section 2.5. Plots of observed versus predicted $\mathrm{O}_{2}$ and $\mathrm{NO}_{3}{ }^{-}$fall very close to the 1:1 line (Supporting Information, Figure S1) because (1) each oxygen concentration is matched by adjusting the $\mathrm{O}_{2}$ reduction rate, and (2) each $\mathrm{NO}_{3}{ }^{-}$value is matched by adjusting the linear scaling factor for the shape function (in combination with adjusting the denitrification rate to estimate excess $\mathrm{N}_{2}$ ). Figure 6 shows the percentiles of the estimated $\mathrm{N}$ input histories (linearly scaled shape function) for 52 wells with $\mathrm{NO}_{3}{ }^{-}$and $\mathrm{N}_{2, \mathrm{D}}$ data. Also shown are historical estimates of $\mathrm{N}$ applied in fertilizer and manure in the study area. As expected, the estimates include a wide range of input concentration histories as a result of varying fractions of agricultural land around the wells

(Figure 1). The trend of the input functions follows the expected inputs from agricultural land use with low inputs in the mid 1900's and increased inputs in the late 1900's. The modern trend of the median $\mathrm{NO}_{3}{ }^{-}$input function after 1970 has the same slope as the applied $\mathrm{N}$ trend. Some input functions included slightly elevated input concentrations of $\mathrm{NO}_{3}{ }^{-}$in water with old (greater than 300 years) residence time. These instances may relate to geological sources of $\mathrm{N}$ (Holloway and Dahlgren, 1999), low $\mathrm{N}$ fluxes dissolved in very small amounts of recharge under arid conditions (Walvoord et al., 2003), or recycling of old groundwater in modern irrigation 
affecting the age tracer concentrations. The features of the estimated input functions were also similar to those estimated from a numerical model in the center of the study area by Green et al. (2010), with slightly elevated concentrations in the oldest waters, low concentrations inputs in the early to mid-1900's, and sharply increasing concentrations after 1960-1970.

The rate coefficient estimates indicate that the reactivity of the aquifer as a whole may be characterized by continuous distributions. Figure 7 shows the composite probability density of the estimated reaction rate coefficients for zero order $\mathrm{O}_{2}$ reduction and denitrification. The composite probability density functions (PDFs) were constructed for each rate parameter by taking the arithmetic average among all samples of the individual PDFs of that parameter. Individual PDFs were estimated from the linear confidence intervals of the parameters. For the 120 estimated $\mathrm{O}_{2}$ rate coefficients, $k_{\mathrm{O}}$, the composite PDF exhibits a roughly bell-curve shaped distribution in log-space with a median of $0.12 \mathrm{mg} \mathrm{L}^{-1} \mathrm{yr}^{-1}$. For the 52 estimated denitrification rate coefficients $k_{\mathrm{N}}$, the composite PDF is broader, more multi-modal and skewed, with a median of $0.32 \mathrm{mg}-\mathrm{N} \mathrm{L}^{-1} \mathrm{yr}^{-1}$. The irregularities of the denitrification rate coefficient PDF may result from a smaller number of estimates. Rate coefficients for first order $\mathrm{O}_{2}$ reduction and denitrification rate coefficients (Figure 7c, d) exhibited similar shapes with medians of $0.023 \mathrm{yr}^{-1}$ and $0.046 \mathrm{yr}^{-1}$ respectively. Overall, the results indicate that a log-normal distribution may be a suitable representation of the $\mathrm{O}_{2}$ reaction kinetic coefficients across a regional aquifer. Additional studies with greater numbers of rate estimates for denitrification will help to better characterize the form of distribution of the reaction rate coefficient.

Comparison of the rate coefficients on the basis of electron equivalents (meq) indicates that the rates of $\mathrm{O}_{2}$ reduction and denitrification are correlated and that rates of denitrification generally exceed rates of $\mathrm{O}_{2}$ reduction. To facilitate comparison, reaction rates were converted 
to electron transfer rates. The electron transfer equivalent for $\mathrm{O}_{2}$ reduction is four times the molar $\mathrm{O}_{2}$ reduction rate, and the electron transfer equivalent for denitrification is five times the molar denitrification rate (as N) based on half-reactions in Postma et al. (1991). Results are shown in Figure 8 for well samples with estimates of both denitrification and $\mathrm{O}_{2}$ reduction rate coefficients. Also shown are results from previous studies including Tesoriero and Pucket (2011), Liao et al. (2012), and McMahon et al. (2004a, b). The collected results demonstrate that the individual wells in the current study have a range of variability that spans the full range of observations from the previous studies. Substantial variability in this study is representative of individual wells with a wide range of geochemical and hydrogeological conditions (Landon et al., 2011), whereas points from Liao et al. (2012) and Tesoriero and Pucket (2011) with reduced variability are average conditions for multiple wells.

The correlation of denitrification rates with $\mathrm{O}_{2}$ reduction rates is consistent with control of the redox reactions by solid phase electron donors that span the $\mathrm{O}_{2}$ and $\mathrm{NO}_{3}{ }^{-}$reduction zones (Green and Bekins, 2010; Tesoriero and Pucket, 2011) rather than by dissolved electron donors originating in recharge and potentially depleted in deeper zones. Denitrification rates tend to exceed $\mathrm{O}_{2}$ reduction rates on an electron equivalent basis, as shown by the tendency of points to plot to the right of the 1:1 line in Figure 8. This may stem from an increase of available electron donors with depth, as denitrification typically occurs deeper than $\mathrm{O}_{2}$ reduction. We also observed that vertical velocities (estimated as sample depth divided by median age) correlated with zero order $\mathrm{NO}_{3}{ }^{-}$reduction rates $\left(\mathrm{R}^{2}=0.5, \mathrm{p}<0.001\right)$, as has been observed in infiltration basins (Schmidt et al., 2011). Modern acceleration of the hydrologic cycle may have accelerated rates of reactions by increasing the juxtaposition of deep solid phase electron donors with electron acceptors arriving from the surface. Additional studies of redox chemistry are needed to better 
understand the mechanisms controlling variations of reaction rates and the high rates of denitrification relative to $\mathrm{O}_{2}$ reduction.

The observed relationship between $\mathrm{O}_{2}$ reduction rates and denitrification rates in Figure 8 may facilitate future efforts to understand and predict natural attenuation of $\mathrm{NO}_{3}{ }^{-}$. The uncertainties of estimated denitrification rates are typically greater than those for $\mathrm{O}_{2}$ reduction. Estimated denitrification rates depend on the RTD of the water, measurements of $\mathrm{NO}_{3}{ }^{-}$, estimates of $\mathrm{N}_{2, \mathrm{D}}$, the $\mathrm{O}_{2}$ reduction rate and $\mathrm{NO}_{3}{ }^{-}$input history. Uncertainties in all these measurements and estimates propagate to uncertainty in the estimate of denitrification rate. For $\mathrm{O}_{2}$ reduction, the input history is better known, and there are fewer variables to contribute uncertainty. We propose that estimates of $\mathrm{O}_{2}$ rates together with estimates of the general relationship between $\mathrm{O}_{2}$ rates and denitrification rates may provide a proxy for tracer based estimates of denitrification rates in basins where this correlation has been established. The relationship between the rates may also be useful as prior information in optimizations and calibration to constrain the values of the estimated reaction parameters (Liao et al., 2012).

\subsection{Multi-model RTDs for regional predictions}

The multi-model RTDs, input histories, and reaction parameters were synthesized to provide an example of a multi-model RTD estimate of regional $\mathrm{NO}_{3}{ }^{-}$trends. The multi-model RTDs (e.g. Figure 4) were combined with the optimized $\mathrm{NO}_{3}{ }^{-}$input functions and reaction parameters (Eq. (1)) for all well samples that included measurements of $\mathrm{O}_{2}, \mathrm{NO}_{3}{ }^{-}$, and more than two age-tracers. For 61 well samples with measurements of $\mathrm{NO}_{3}{ }^{-}$but no estimates of $\mathrm{N}_{2, \mathrm{D}}$,

(Table S1) a value of $\mathrm{N}_{2, \mathrm{D}}$ was assigned equal to the mean of the measured values $\left(1.9 \mathrm{mg} \mathrm{L}^{-1}\right)$ in order to include those well samples in the analysis. Because the models are calibrated to the 
observed $\mathrm{NO}_{3}{ }^{-}$, the addition of a small quantity of $\mathrm{N}_{2, \mathrm{D}}$ with appropriate reaction rate is not expected to strongly affect results. For forecasting purposes, inputs $\mathrm{Of}^{-}{ }_{3}^{-}$were assumed to remain constant after 2007.

The multi-model analysis of $\mathrm{NO}_{3}{ }^{-}-\mathrm{N}$ inputs and reactions gives reasonable estimates of $\mathrm{NO}_{3}{ }^{-}-\mathrm{N}$ trends in the regional study area. Figure 9 shows the predictions of $\mathrm{NO}_{3}{ }^{-}-\mathrm{N}$ concentrations. Also shown are historical observations of $\mathrm{NO}_{3}{ }^{-}-\mathrm{N}$ concentrations in eastern Central Valley alluvial fans compiled by Burow et al. (2012). The modeled $\mathrm{NO}_{3}{ }^{-}-\mathrm{N}$ trends show a wide range of variability, as has also been observed in regional, time-series datasets in this area (Landon et al., 2011). The median of the modeled $\mathrm{NO}_{3}{ }^{-}-\mathrm{N}$ falls between the confidence intervals of the median of historical observations analyzed by Burow et al (2012). The slope of the modeled median from 1995 to 2005 was $0.08 \mathrm{mg} \mathrm{L}^{-1} \mathrm{yr}^{-1}$ (interquartile range of 0.03 to 0.14 ) which was between the observed slopes of the lower (0.02) and upper (0.09) confidence intervals from Burow et al (2012) for the same time period. The modeled trend of the median from 1955 to 2005 was $0.05 \mathrm{mg} \mathrm{L}^{-1} \mathrm{yr}^{-1}$ for the model, also in the range of the confidence intervals from observations ( 0.03 to $0.08 \mathrm{mg} \mathrm{L}^{-1} \mathrm{yr}^{-1}$ ) during the same time span. For further evaluation of the RTD model based estimates, we compared the predicted trends from the RTD models with actual trends from study wells that had been sampled previously $(n=20)$. The observed median trend (not shown) was $0.06 \mathrm{mg} \mathrm{L}^{-1} \mathrm{yr}^{-1}$ with the interquartile range of -0.05 to $0.21 \mathrm{mg} \mathrm{L}^{-1} \mathrm{yr}^{-1}$, similar to the modeled trend. The trends of the modeled historical $\mathrm{NO}_{3}{ }^{-}-\mathrm{N}$ concentrations are also similar to the curves estimated based on national datasets, in other agricultural areas with increasing fertilizer use (Hinkle and Tesoriero, 2013). The similarity among these observations and the model results of the current study suggests that the multi-model RTD approach to estimating $\mathrm{NO}_{3}{ }^{-} \mathrm{N}$ inputs and reactions is robust. It is important to note, however, that the 
regional estimates of trends in this study contain less variability than the observed trends, likely as a result of imposing a single shape function for all wells in the RTD-based approach. Future studies may explore options of generating predictions with greater variability of $\mathrm{NO}_{3}{ }^{-} \mathrm{N}^{-}$by integrating additional historical data of $\mathrm{NO}_{3}{ }^{-} \mathrm{N}$ concentrations at study well locations.

\section{Summary and Conclusions}

This study demonstrates that a multi-model, residence time distribution based approach can provide robust and useful estimates of regional characteristics of residence time and geochemistry. While similar previous studies have focused on the use of individual RTD models or comparisons among individual models, this is the first study to our knowledge that explores multi-model averaging for RTD models in a regional context. Comparisons of six averaging approaches (EWA, AIC, AIC-S, GRA, GRAneg, and KIC) using a synthetic dataset indicated that differences among the methods were moderate. AIC averaging was selected for the RTD models used to predict residence time characteristics and $\mathrm{NO}_{3}{ }^{-}$concentrations. When AIC averaged analytical RTD models were applied to the data set of tracers from well samples in the study area, calibration errors were less than those for individual RTD models, and were similar to synthetic test cases with moderate prediction errors. Estimates of $\mathrm{O}_{2}$ reduction and denitrification rate coefficients with the AIC-averaged RTD model were consistent with ranges observed in previous studies and demonstrated that the two rates tend to be correlated. Historical trends in $\mathrm{NO}_{3}{ }^{-}$concentrations produced by the AIC averaged RTD model were similar to observations for the eastern fans of the Central Valley California, to trends in resampled study wells, and to observations in other agricultural regions. These results indicate that the multi- 
model RTD approach provides a robust and computationally efficient method, given adequate data, to estimate $\mathrm{NO}_{3}{ }^{-}$reactivity and trends in a regional context.

The application of the multi-model RTD approach yielded new information about relationships among $\mathrm{O}_{2}$ reduction rates and denitrification rates in a regional setting and helped to advance the theory of redox progression in recharging groundwater. In particular, the regional analysis demonstrated that these rates vary widely and are correlated, and the rates of denitrification tend to exceed the rates of $\mathrm{O}_{2}$ reduction on an electron milliequivalent basis. The tendency for denitrification rates to exceed $\mathrm{O}_{2}$ reduction rates may relate to the long term effects of recharging electron acceptors on concentrations of solid-phase electron donors. For example, lower rates of $\mathrm{O}_{2}$ reduction may stem from depletion of electron donors near the water table. Additional studies are needed, however, to better understand the spatial and temporal evolution of redox reaction rates.

Another consideration for future studies is the usefulness of the multi-model RTD approach relative to numerical distributed parameter approaches. A potential advantage of the multi-model average analytical travel time distribution (TTD) approach is that it may give more accurate predictions at individual wells because it focuses on the portions of the domain that are most relevant for that well and avoids external features such as geological interpretations that can introduce uncertainty of local estimates in a regional numerical model. However, a multi-model TTD approach typically has less flexibility for incorporating hydrogeological or chemical information, is less capable of extending results to unsampled areas, and is less applicable to point-source solutes. An optimal approach may be to combine the strengths of the multi-model TTD approach for minimizing local prediction errors with the strengths of distributed parameter 
numerical models to incorporate general hydrologic information and to extrapolate results to unsampled areas.

\section{Acknowledgements}

Funding was provided by the National Water-Quality Assessment (NAWQA) program, National Research Program (NRP), USGS Toxic Substances Hydrology program, and the National Science Foundation under Grant DMS-1460319. Thanks to Karen Burow for assistance with well information and observed decadal trends and to Matthew Landon for help with datasets and geochemical information. Discussions with Ate Visser contributed to the improvement of this study. 


\section{References}

Aeschbach-Hertig, W., Peeters, F., Beyerle U., and Kipfer, R., 1999. Interpretation of dissolved atmospheric noble gases in natural waters. Water Resour. Res. 35 (9), 2779 - 2792.

Akaike, H., 1974. A new look at the statistical model identification. IEEE Transactions on Automatic Control 19, 716-723.

Alikhani, J., Deinhart, A., Visser, A., Bibby, R., Purtshert, R., Moran, J., Massoudieh, A., and Esser, B., 2016. Nitrate vulnerability projections from Bayesian inference of multiple groundwater age tracers. J. Hydrol. In press.

Berkowitz, B., Cortis, A., Dentz, M., and Scher, H., 2006. Modeling non-Fickian transport on geological formations as a continuous time random walk. Rev. Geophys. 44(2), RG2003. doi:10.1029/2005RG000178.

Böhlke, J.K., 2002. Groundwater recharge and agricultural contamination. Hydrogeol. J. 10(3), 438-439.

Böhlke, J.K., and Denver, J.M., 1995. Combined use of groundwater dating, chemical, and isotopic analyses to resolve the history and fate of nitrate contamination in 2 agricultural watersheds, Atlantic Coastal-Plain, Maryland, Water Resour. Res. 31(9), 2319-2339.

Böhlke, J.K., Wanty, R., Tuttle, M., Delin, G., and Landon M., 2002. Denitrification in the recharge area and discharge area of a transient agricultural nitrate plume in a glacial outwash sand aquifer, Minnesota, Water Resour. Res. 38(7), 1105. doi: 10.1029/2001WR000663.

Böttcher, J., Strebel, O., Voerkelius, S., and Schmidt, H.L., 1990. Using isotope fractionation of nitratenitrogen and nitrate-oxygen for evaluation of microbial denitrification in a sandy aquifer, J. Hydrol. 114(3), 413-424.

Browne, B.A., and Guldan, N.M., 2005. Understanding long-term baseflow water quality trends using a synoptic survey of the ground water-surface water interface, Central Wisconsin, J. Environ. Qual. 34(3), 825-35.

Burow, K.R., Jurgens, B.C., Belitz, K., Dubrovsky, N.M., 2012. Assessment of regional change in nitrate concentrations in groundwater in the Central Valley, California, USA, 1950s-2000s. Environ. Earth Sci. doi:10.1007/s12665-012-2082-4

Burt, T.P., Heathwaite, A.L., and Trudgill, S.T., (Eds), 1993. Nitrate: Processes, Patterns, and Management. John Wiley and Sons, New York, NY. 444 p.

Busenberg, E., and Plummer, L.N., 1992. Use of chlorofluorocarbons $\left(\mathrm{CFC}_{3} \mathrm{~F}\right.$ and $\left.\mathrm{CCl}_{2} \mathrm{~F}_{2}\right)$ as hydrologic tracers and age-dating tools-The alluvium and terrace system of central Oklahoma: Water Resour. Res. 28(9), 2257-2283. 
Busenberg, E., and Plummer, L.N., 2008. Dating groundwater with trifluoromethyl sulfurpentafluoride $\left(\mathrm{SF}_{5} \mathrm{CF}_{3}\right)$, sulfur hexafluoride $\left(\mathrm{SF}_{6}\right), \mathrm{CF}_{3} \mathrm{Cl}(\mathrm{CFC}-13)$, and $\mathrm{CF}_{2} \mathrm{Cl}_{2}(\mathrm{CFC}-12)$, Water Resour. Res. 44, W02431. doi:10.1029/2007WR006150.

Cook, P.G., and Böhlke, J.K., 2000. Determining timescales for groundwater flow and solute transport, in Cook, P.G., and Herczeg, A., eds., Environmental tracers in subsurface hydrology: Kluwer Academic Publishers, Boston, p. 1-30.

Diks C.G.H. and Vrugt, J.A., 2010. Comparison of point forecast accuracy of model averaging methods in hydrologic applications. Stoch. Environ. Res. Risk Assess. 24, 809-820.

Doherty, J., 2008. PEST: Model-Independent Parameter Estimation User Manual: 5th Edition, 336 pp., Watermark Computing, Corinda, Australia.

Dubrovsky, N.M., Burow, K.R., Clark, G.M., Gronberg, J.A.M., Hamilton, P.A., Hitt, K.J., Mueller, D.K., Munn, M.D., Nolan, B.T., Puckett, L.J., Rupert, M.G., Short, T.M., Spahr, N.E., Sprague, L.A., and Wilber, W.G., 2010. Nutrients in the Nation's Streams and Groundwater, 1992-2004. U.S. Geol. Surv.Circ., 1350.

Engdahl, N. B., Ginn, T.R., and Fogg, G.E., 2012. Non-Fickian dispersion of groundwater age, Water Resour. Res. 48, W07508. doi:10.1029/2012WR012251.

Fan A. M. and Steinberg V. E., 1996. Health implications of nitrate and nitrite in drinking water: an update on methemoglobinemia occurrence and reproductive and developmental toxicity. Regulatory Toxicology and Pharmacology. 23, 35-43.

Fisher, C.H., and Healy, R.W., 2008. Water movement within the unsaturated zone in four agricultural areas of the United States. J. Environ. Qual. 37(3), 1051-63. doi: 10.2134/jeq2006.0561.

Foglia, L., Mehl, S.W., Hill, M.C., and Burlando, P., 2013. Evaluating model structure adequacy: The case of the Maggia Valley groundwater system, southern Switzerland. Water Resour. Res. 49. doi:10.1029/2011WR011779.

Gilmore, T.E., Genereux, D.P., Solomon, D.K., and Solder J.E., 2015. Groundwater transit time distribution and mean from streambed sampling in an agricultural coastal plain watershed, North Carolina, USA, Water Resour. Res. 52. doi:10.1002/2015WR017600.

Goderniaux, P., Davy, P., Bresciani, E., de Dreuzy, J.-R., and Le Borgne, T., 2013. Partitioning a regional groundwater flow system into shallow local and deep regional flow compartments, Water Resour. Res. 49, 2274-2286. doi:10.1002/wrcr.20186.

Granger, C.W.J. and Ramanathan, R., 1984. Improved methods of combining forecasts, Journal of Forecasting 3, 197-204.

Green, C.T., Böhlke, J.K., Bekins, B.A., and Phillips S.P., 2010. Mixing effects on apparent reaction rates and isotope fractionation during denitrification in a heterogeneous aquifer. Water Resour. Res. 
46, W08525. doi:10.1029/2009WR008903.

Green, C.T., Fisher, L.H., and Bekins, B.A., 2008a. Nitrogen fluxes through unsaturated zones in five agricultural settings across the United States. J. Environ. Qual. 37(3), 1073-1073.

Green, C. T., Puckett, L.J., Böhlke, J.K., Bekins, B.A., Phillips, S.P., Kauffman, L.J., Denver, J.M., and Johnson, H.M., 2008b. Limited occurrence of denitrification in four shallow aquifers in agricultural areas of the United States. J. Environ. Qual. 37(3), 994-1009.

Green, C.T., and Bekins, B.A., 2010. Sustainability of natural attenuation of nitrate in agricultural aquifers: U.S. Geological Survey Fact Sheet 2010-3077, 4 p.

Green, C. T., Zhang, Y., Jurgens, B.C., Starn, J.J., and Landon, M.K., 2014. Accuracy of travel time distribution (TTD) models as affected by TTD complexity, observation errors, and model and tracer selection, Water Resour. Res. 50, 6191-6213. doi:10.1002/2014WR015625.

Green, C. T., Walvoord, M.A., Andraski, B.J., Striegl, R.G., and Stonestrom, D.A., 2015. Multimodel analysis of anisotropic diffusive tracer-gas transport in a deep arid unsaturated zone, Water Resour. Res. 51. doi:10.1002/2014WR016055.

Groffman, P.M., Altabet, M.A., Böhlke, J.K., Butterbach-Bahl, K., David, M.B., Firestone, M.K., Giblin, A.E., Kana, T.M., Nielsen, L.P., Voytek, M.A., 2006. Methods for measuring denitrification:

Diverse approaches to a difficult problem. Ecol. Appl. 16(6), 2091-2122.

Haggerty, R., McKenna, S.A., and Meigs, L.C., 2000. On the late-time behavior of tracer test breakthrough curves. Water Resour. Res. 36, 3467-3479.

Hallberg, G.R., 1986. Overview of agricultural chemicals in ground water. Proceedings of Conference on Agricultural Impacts on Ground Water, Omaha, Nebraska. National Water Well Association, Dublin, Ohio, p. 1-63.

Hatfield, J.L., and Follett, R.F., (Eds) 2008. Nitrogen in the Environment: Sources, Problems, and Management, 2nd Edition. Elsevier, Amsterdam, 702 p.

Hill, M.C., and Tiedeman, C.R., 2007. Effective Groundwater Model Calibration. Wiley, Hoboken, NJ, $455 \mathrm{p}$.

Hinke, S.R., and Tesoriero, A.J., 2013. Nitrogen speciation and trends, and prediction of denitrification extent, in shallow US groundwater. J. Hydrol. 509, 343-353. doi:10.1016/j.jhydrol.2013.11.048.

Holloway, J.M. and Dahlgren, R.A., 1999. Geologic nitrogen in biogeochemical cycling. Geology 27, 567-570.

Jurgens B.C., Burow K.R., Dalgish B.A., Shelton J.L., 2008. Hydrogeology, water chemistry, and factors affecting the transport of contaminants in the zone of contribution of a public-supply well in Modesto, eastern San Joaquin Valley, California. US Geol Surv Sci Invest Rep 2008-5156, p 78. 
Jurgens, B.C., Fram, M.S., Belitz, K., Burow, K.R., and Landon, M.K., 2010. Effects of groundwater development on uranium: Central Valley, California, USA. Ground Water 48(6), 913-928.

Kashyap, R.L., 1982. Optimal choice of AR and MA parts in autoregressive moving average models. IEEE Trans. Pattern Anal. Mach. Intell. 4(2), 99-104. doi:10.1109/TPAMI.1982.4767213.

Kennedy, C.D., Genereux, D.P., Corbett, D.R., and Mitasova, H., 2009. Relationships among groundwater age, denitrification, and the coupled groundwater and nitrogen fluxes through a streambed. Water Resour. Res. 45, W09402. doi:10.1029/2008WR007400.

Korom, S.F., Schlag, A.J., Schuh, W.M., and Schlag, A.K., 2005. In situ mesocosms: Denitrification in the Elk Valley aquifer. Ground Water Monit. Rem. 25,79-89.

Kreft A. and Zuber, A., 1978. On the physical meaning of the dispersion equation and its solutions for different initial and boundary conditions. Chemical Engineering Science 33, 1471-1480.

Landon, M.K., and Belitz, K., 2008. Ground-water quality data in the Central Eastside San Joaquin Basin 2006: Results from the California GAMA Program. U.S. Geological Survey Data Series 325, 88 p.

Landon, M.K., Belitz, K., Jurgens, B.C., Kulongoski, J.T., and Johnson, T.D., 2010a. Status and understanding of groundwater quality in the Central-Eastside San Joaquin Basin, 2006: California GAMA Priority Basin project. U.S. Geological Survey Scientific Investigations Report 2009-5266, 97 p.

Landon, M.K., Jurgens, B., Katz, B.G., Eberts, S.M., Burow, K.R., Crandall, C.A., 2010b. Depthdependent sampling to identify short-circuit pathways to public-supply wells in multiple aquifer settings in the United States. Hydrogeol. J. 18: 577-593.

Landon, M.K., Green, C.T., Belitz, K., Singleton, M.J., and Esser, B.K., 2011. Relations of hydrogeologic factors, groundwater reduction-oxidation conditions, and temporal and spatial distributions of nitrate, Central-Eastside San Joaquin Valley, California, USA. Hydrogeol. J. 19(6), 1203-1224 doi: 0.1007/s10040-011-0750-1.

Levin, I., and Kromer, B., 2004. Tropospheric ${ }^{14} \mathrm{CO}_{2}$ Level in Mid-Latitudes of the Northern Hemisphere (1959-2003). Radiocarbon 46(3), 1261-1272.

Levin, I., Hammer, S., Kromer, B., and Meinhardt, F., 2008. Radiocarbon observations in atmospheric $\mathrm{CO} 2$ : determining fossil fuel $\mathrm{CO} 2$ over Europe using Jungfraujoch observations as background. Sci. Total Environ. 391(2-3),211-6.

Liao, L., Green, C.T., Bekins, B.A., and Bohlke, J.K., 2012. Factors controlling nitrate fluxes in groundwater in agricultural areas. Water Resour. Res. 48, W00109. doi: 10.1029/2011wr011008.

Maloszewski, P., and Zuber, A., 1982. Determining the turnover time of groundwater systems with the aid of environmental tracers. 1. Models and their applicability. J. Hydrol. 57,207-231. 
Marçais, J., de Dreuzy, J.R., Ginn, T.R., Rousseau-Gueutin, P., Leray, S., 2015. Inferring transit time distributions from atmospheric tracer data: assessment of the predictive capacities of Lumped Parameter Models on a 3D crystalline aquifer model. J. Hydrol. 525, 619-631. doi:10.1016/j.jhydrol.2015.03.055.

Mariotti, A., Landreau, A., and Simon, B., 1988. ${ }^{15} \mathrm{~N}$ isotope biogeochemistry and natural denitrification process in groundwater: Application to the chalk aquifer of northern France. Geochim. Cosmochim. Acta 52(7), 1869-1878.

Massoudieh, A., Visser, A., Sharifi, S., and Broers, H.P., 2013. A Bayesian modeling approach for estimation of a shape-free groundwater age distribution using multiple tracers. Appl. Geochem. 50, 252-264. doi:10.1016/j.apgeochem.2013.10.004.

McCallum, J.L., Engdahl, N.B., Ginn, T.R., and Cook, P.G., 2014. Nonparametric estimation of groundwater residence time distributions: What can environmental tracer data tell us about groundwater residence time? Water Resour. Res. 50. doi:10.1002/2013WR014974.

McMahon, P.B., Böhlke, J.K., and Christenson, S.C., 2004a. Geochemistry, radiocarbon ages, and paleorecharge conditions along a transect in the central High Plains aquifer, southwestern Kansas, USA. Appl. Geochem. 19(11), 1655-1686.

McMahon, P.B., Böhlke, J.K., and Lehman, T.M., 2004b. Vertical gradients in water chemistry and age in the southern High Plains aquifer, Texas, 2002. U.S. Geol. Surv. Sci. Invest. Rep., 2004-5053, $53 \mathrm{p}$.

McMahon, P.B., Böhlke, J.K., Kauffman, L.J., Kipp, K.L., Landon, M.K., Crandall, C.A., Burow, K.R., and Brown C.J., 2008. Source and transport controls on the movement of nitrate to public supply wells in selected principal aquifers of the United States. Water Resour. Res. 44(4), W04401. doi:10.1029/2007WR006252.

Menció, A., Mas-Pla, J., Otero, N. and Soler, A., 2011. Nitrate as a tracer of groundwater flow in a fractured multilayered aquifer. Hydrol. Sci. J. 56(1), 108-122.

Mengis, M., Schiff, S.L., Harris, M., English, M.C., Aravena, R., Elgood, R.J., and MacLean, A., 1999. Multiple geochemical and isotopic approaches for assessing ground water $\mathrm{NO}_{3}{ }^{-}$elimination in a riparian zone. Ground Water 37(3), 448-457.

Michel, R. L., 1989. Tritium deposition in the continental United States, 1953-1983. USGS WaterResources Investigations Report 89-4072.

National Research Council (NRC), 2000. Natural Attenuation for Groundwater Remediation. Natl. Acad. of Sci., Washington, D. C., 292 pp.

Neuman, S.P., and Tartakovsky, D.M., 2009. Perspective on theories of non-Fickian transport in heterogeneous media. Adv Water Resour. 32(5), 670-680. 
Osenbrück, K., Fiedler, S., Knöller, K., Weise, S.M., Sültenfuß, J., Oster, H., and Strauch, G., (2006), Timescales and development of groundwater pollution by nitrate in drinking water wells of the Jahna-Aue, Saxonia, Germany, Water Resour. Res. 42, W12416. doi:10.1029/2006WR004977.

Otero N., Torrento C., Soler A., Mencio A., and Mas-Pla J., 2009. Monitoring groundwater nitrate attenuation in a regional system coupling hydrogeology with multi-isotopic methods: the case of Plana de Vic (Osana, Spain). Agricult. Ecosys. Environ. 133, 103-113.

Phillips, S.P., Green, C.T., Burow, K.R., Shelton, J.L., and Rewis, D.L., 2007. Simulation of Multiscale Ground-Water Flow in Part of the Northeastern San Joaquin Valley, California. U.S. Geological Survey, Scientific Investigations Report 2007-5009.

Poeter, E and Anderson, D., 2005. Multi-model Ranking and Inference in Ground Water Modeling. Ground Water 43(4), 597-605.

Poeter, E.P., and Hill, M.C., 2007. MMA, a computer code for multi-model analysis. U.S. Geol. Surv. Tech. Methods, TM6-E3, 113 pp.

Postma D., Boesen C., Kristiansen H., Larsen F., 1991. Nitrate reduction in an unconfined sandy aquifer: water chemistry, reduction processes, and geochemical modeling. Water Resour. Res. 27, 2027 2045.

Refsgaard, J. C., Christensen, S., Sonnenborg, T.O., Seifert, D., Hojberg, A.L., and Troldborg., L., 2012. Review of strategies for handling geological uncertainty in groundwater flow and transport modeling. Adv. Water Resour. 36, 36-50.

Refsgaard, J.C., Auken, E., Bamberg, C.A., Christensen, B.S., Clausen, T., Dalgaard, E., Efferso, F., Ernstsen, V., Gertz, F., Hansen, A.L., He, X., Jacobsen, B.H., Jensen, K.H., Jorgensen, F., Jorgensen, L.F., Koch, J., Nilsson, B., Petersen, C., De Schepper, G., Schamper, C., Sorensen, K.I., Therrien, R., Thirup, C., Viezzoli, A., 2014. Nitrate reduction in geologically heterogeneous catchments - a framework for assessing the scale of predictive capability of hydrological models. Sci. Total Environ. 468-469, 1278-88. doi:10.1016/j.scitotenv.2013.07.042

Reimer, P.J., Baillie, M.G.L., Bard, E., Bayliss, A., Beck, J.W., Blackwell, P.G., Bronk Ramsey, C., Buck, C.E., Burr, G., Edwards, R.L., Friedrich, M., Grootes, P.M., Guilderson, T.P., Hajdas, I., Heaton, T.J., Hogg, A.G., Hughen, K.A., Kaiser, K.F., Kromer, B., McCormac, F.G., Manning, S.W., Reimer, R.W., Richards, D.A., Southon, J., Turney, C.S.M., van der Plicht, J., and Weyhenmeyer, C., 2009. IntCal09 and Marine09 radiocarbon age calibration curves, 0 - 50,000 years cal BP. Radiocarbon 51(4), 1111-50.

Rivett, M.O., Buss, S.R., Morgan, P.P., Smith, J.W.N., and Bemment, C.D., 2008. Nitrate attenuation in groundwater: a review of biogeochemical controlling processes. Water Res. 42, 4215-42321. 
Rojas R., Kahundeb, S., Peetersa, L., Batelaana, O., Feyend, L., and Dassarguesa, A., 2010. Application of a multi-model approach to account for conceptual model and scenario uncertainties in groundwater modeling. J. Hydrol. 394(3-4), 416-435.

Schmidt, C.M., Fisher, A.T., Racz, A.J., Lockwood, B.S., and Los Huertos, M, 2011. Linking denitrification and infiltration rates during managed groundwater recharge. Environ mental Science \& Technology. 45, 9634-9640. doi: 10.1021/es2023626.

Seifert, D., Sonnenborg, T.O., Refsgaard, J.C., Højberg, A.L., and Troldborg., L., 2012. Assessment of hydrological model predictive ability given multiple conceptual geological models. Water Resour. Res. 48, W06503. doi:10.1029/2011WR011149.

Seitzinger, S., Harrison, J.A., Bohlke, J.K., Bouwman, A.F., Lowrance, R., Peterson, B., Tobias, C., and Van Drecht G., 2006. Denitrification across landscapes and waterscapes: A synthesis. Ecol. Appl. 16(6), 2064-2090.

Singleton, M.J., Esser, B.K., Moran, J.E., Hudson, G.B., McNab, W.W., Harter, T., 2007. Saturated zone denitrification: potential for natural attenuation of nitrate contamination in shallow groundwater under dairy operations. Environ. Sci. Technol. 41(3), 759-765.

Smedley P.L., Kinniburgh D.G., 2002. A review of the source, behavior, and distribution of arsenic in natural waters. Appl. Geochem. 17(5), 517-568.

Smith, R.L., Howes, B.L., and Duff, J.H., 1991. Denitrification in nitrate-contaminated groundwater occurrence in steep vertical geochemical gradients. Geochim. Cosmochim. Acta, 55(7), 18151825.

Solomon, D.K., Hunt, A., and Poreda, R.J., 1996. Source of radiogenic helium 4 in shallow aquifers: Implications for dating young groundwater. Water Resour. Res. 32(6), 1805-1813.

Starn, J.J., Green, C.T., Hinkle, S.R., Bagtzoglou, A.C., and Stolp, B.J., 2014. Simulating Water-Quality Trends in Public-Supply Wells in Transient Flow Systems. Groundwater 52, 53-62. doi: 10.1111/gwat.12230.

Tesoriero, A.J., Saad, D.A., Burow, K.R., Frick, E.A., Puckett, L.J., and Barbash, J.E., 2007. Linking ground-water age and chemistry data along flow paths: Implications for trends and transformations of nitrate and pesticides. J. Contam. Hydrol. 94(1-2), 139-155.

Tesoriero, A.J., and Puckett, L.J., 2011. $\mathrm{O}_{2}$ reduction and denitrification rates in shallow aquifers. Water Resour. Res. 47, W12522. doi:10.1029/2011WR010471.

Troldborg, L., Refsgaard, J.C., Jensen, K.H., and Engesgaard, P., 2007., The importance of alternative conceptual models for simulation of concentrations in multi-aquifer system. Hydrogeol. J. 15, 843-860. 
Visser, A., Broers, H.P., Purtschert, R., Sültenfuß, J., and de Jonge, M., 2013. Groundwater age distributions at a public drinking water supply well field derived from multiple age tracers $\left({ }^{85} \mathrm{Kr}\right.$, ${ }^{3} \mathrm{H} /{ }^{3} \mathrm{He}$, noble gases and ${ }^{39} \mathrm{Ar}$ ). Water Resour. Res. 49, 7778-7796. doi:10.1002/2013WR014012.

Vogel, J.C., Talma, A.S., and Heaton, T.H.E., 1981. Gaseous nitrogen as evidence for denitrification in groundwater. J. Hydrol. 50(1-3), 191-200.

Walvoord, M.A., Phillips, F.M., Stonestrom, D.A., Evans, R.D., Hartsough, P.C., Newman, B.D., and Striegl, R.G., 2003. A reservoir of nitrate beneath desert soils. Science 302(7), 1021-1024

Welch H.L., Green C.T., Coupe R.H., 2011. The fate and transport of nitrate in shallow groundwater in northwestern Mississippi, USA. Hydrogeol. J. 2011(19), 1239-52. doi: 10.1007/s10040-0110748-8.

Wright M.T., Belitz K., and Johnson, T., 2004. Assessing the susceptibility to contamination of two aquifer systems used for public water supply in the Modesto and Fresno Metropolitan Areas, California, 2001 and 2002. US Geol Surv Sci Invest Rep 2004-5149:35

Ye, M., Meyer, P.D., and Neuman, S.P., 2008. On model selection criteria in multi-model analysis. Water Resour. Res. 44, W03428. doi:10.1029/2008WR006803.

Ye, M., Pohlman, K., Chapman, J., Pohll, G., Reeves, D., 2010. A model-averaging method for assessing groundwater conceptual model uncertainty. Ground Water 48, 716-728.

Young, C., Kroeger, K.D., and Hanson, G., 2013. Limited denitrification in glacial deposit aquifers having thick unsaturated zones (Long Island, USA). Hydrogeol. J. 21(8), 1773-1786.

Zhang, Y., Benson, D.A., and Baeumer, B., 2007. Predicting the tails of breakthrough curves in regionalscale alluvial systems. Ground Water, 45(4), 473-484.

Zhang, Y., Green, C.T., and Baeumer, B., 2014. Linking aquifer spatial properties and non-Fickian transport in mobile-immobile like alluvial settings. J. Hydro. 512, 315-331. doi: 10.1016/j.jhydrol.2014.02.064.

Zhang, Y., Green, C.T., and Fogg, G.E., 2013. The impact of medium architecture of alluvial settings on non-Fickian transport. Adv. Water Resour. 54, 78-99. doi: 10.1016/j.advwatres.2013.01.004. 


\section{Tables and Figures}

Table 1. Residence time distribution (RTD) models and parameters used in this study.

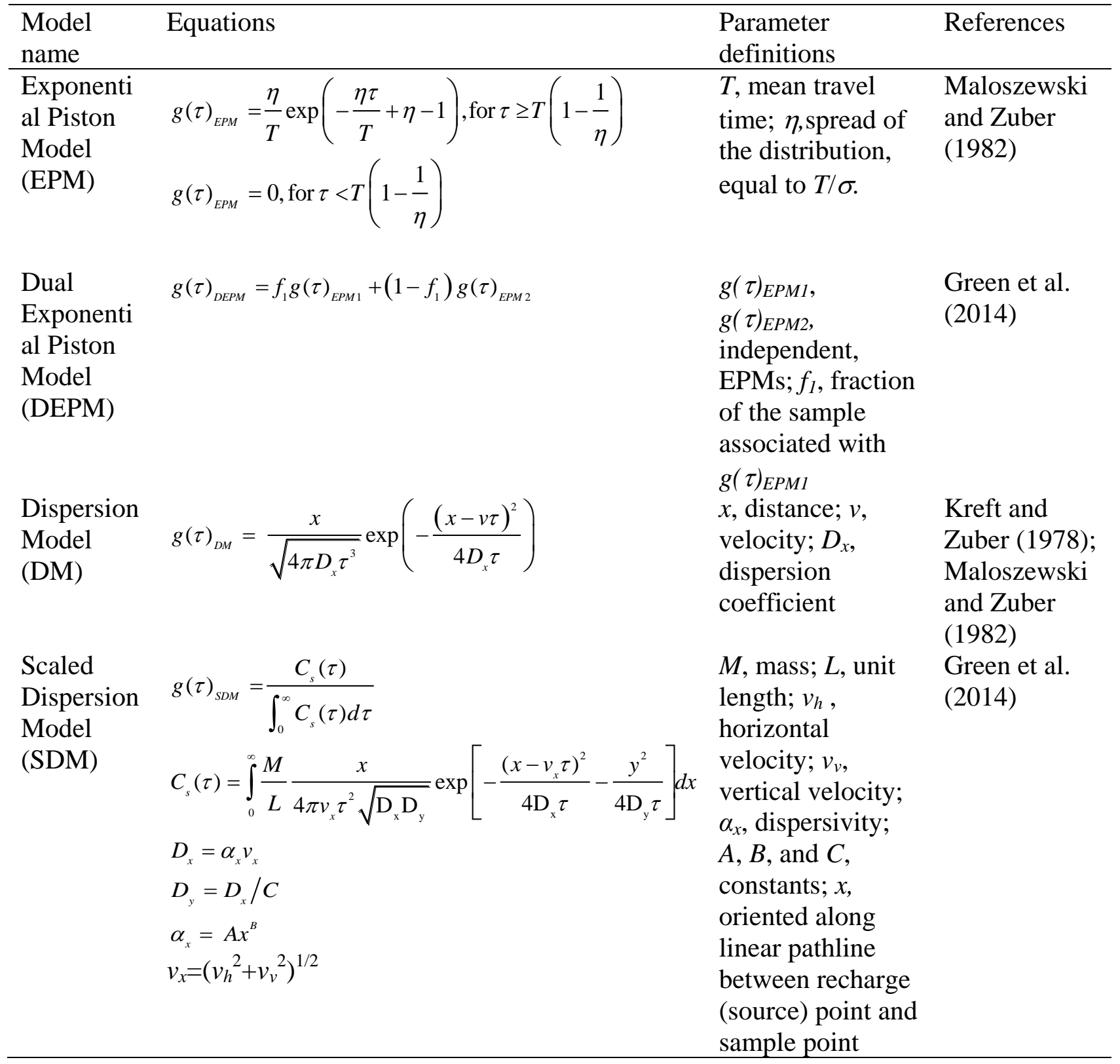


Table 2. Six multi-model approaches tested for averaging RTD models calibrated to age-tracers.

\begin{tabular}{|c|c|c|c|}
\hline Multi-model approach & $\begin{array}{l}\text { Equations for model } \\
\text { weights }\end{array}$ & Definitions & References \\
\hline $\begin{array}{l}\text { Equal weights averaging } \\
\text { (EWA) }\end{array}$ & $w_{j}=\frac{1}{m_{j}}$ & $m_{j}$, number of models. & $\begin{array}{l}\text { Seifert et al. } \\
(2012)\end{array}$ \\
\hline $\begin{array}{l}\text { Granger-Ramanathan } \\
\text { averaging with negative } \\
\text { and positive weights } \\
\text { (GRAneg) and with } \\
\text { positive weights (GRA) }\end{array}$ & $\begin{array}{l}\mathbf{w}=\left(\mathbf{X}_{g r a}{ }^{\mathrm{T}} \mathbf{X}_{g r a}\right)^{-1} \mathbf{X}_{g r a}{ }^{\mathrm{T}} \mathbf{Y} \\
\sum w_{j}=1\end{array}$ & $\begin{array}{l}\mathbf{X}_{g r a}, m_{j} \times m_{i} \text { matrix of } \\
\text { simulated equivalents. } \\
\mathbf{Y}, \text { vector of } m_{i} \\
\text { observations. }\end{array}$ & $\begin{array}{l}\text { Granger and } \\
\text { Ramanathan } \\
\text { (1984); Diks } \\
\text { and Vrugt } \\
\text { (2010) }\end{array}$ \\
\hline $\begin{array}{l}\text { Akaike information } \\
\text { criterion weights (AIC) } \\
\text { and selection (AIC-S) }\end{array}$ & $\begin{array}{l}w_{j}=\frac{\exp \left(-0.5 \Delta_{j}\right)}{\sum_{j=1}^{m j} \exp \left(-0.5 \Delta_{j}\right)} \\
\Delta_{j}=a i c_{j}-a i c_{\min } \\
\text { aic }=m_{i} \ln \left(\sigma^{2}\right)+2 k\end{array}$ & $\begin{array}{l}\text { aic, information criterion. } \\
\sigma^{2} \text {, residual variance. } \\
k, 1+\text { number of model } \\
\text { parameters. } \\
\text { aic } c_{\min } \text {, minimum aic } \\
\text { value among the } m_{j} \\
\text { models. }\end{array}$ & $\begin{array}{l}\text { Akaike } \\
\text { (1974); } \\
\text { Poeter and } \\
\text { Anderson } \\
\text { (2005) }\end{array}$ \\
\hline $\begin{array}{l}\text { Kashyap information } \\
\text { criterion weights (KIC) }\end{array}$ & $\begin{array}{l}w_{j}=\frac{\exp \left(-0.5 \Delta_{j}\right)}{\sum_{j=1}^{m j} \exp \left(-0.5 \Delta_{j}\right)} \\
\Delta_{j}=k i c_{j}-k i c_{\min } \\
k i c=\left(m_{i}-(k-1)\right) \ln \left(\sigma^{2}\right)- \\
(k-1) \ln (2 \pi)+\ln \left|\mathbf{X}^{\mathrm{T}} \boldsymbol{\omega} \mathbf{X}\right|\end{array}$ & $\begin{array}{l}\text { kic, information criterion. } \\
k i c_{\text {min }} \text {, minimum kic value } \\
\text { among the } m_{j} \text { models. } \\
X, m_{i} \times m_{p} \text { matrix of } \\
\text { observation sensitivities } \\
\partial y^{\prime} / \partial b \text { for } m_{p} \text { parameters. } \\
\omega, \text { matrix of } m_{i} \times m_{i} \\
\text { observation weights (see } \\
\text { Hill and Tiedeman, 2007). }\end{array}$ & $\begin{array}{l}\text { Kashyap } \\
\text { (1982); Ye } \\
\text { et al. (2008) }\end{array}$ \\
\hline
\end{tabular}


Table 3. Medians of root-mean-square errors (RMSE) of predictions from multi-model averages applied to synthetic data from Green et al. (2014).

\begin{tabular}{llll}
\hline & Median age, $\tau(\mathrm{yr})$ & $\mathrm{NO}_{3}{ }^{-}\left(\mathrm{mg}^{-N^{-1}}\right)$ & $\mathrm{NO}_{3}{ }^{-} 50 \mathrm{yr}\left(\mathrm{mg}^{-N} \mathrm{~L}^{-1}\right)$ \\
\hline EWA & $3.4 \mathrm{a}$ & $1.19 \mathrm{a}$ & $1.54 \mathrm{ab}$ \\
GRAneg & $3.3 \mathrm{a}$ & $0.82 \mathrm{a}$ & $1.83 \mathrm{ab}$ \\
GRA & $3.5 \mathrm{a}$ & $0.96 \mathrm{a}$ & $1.77 \mathrm{~b}$ \\
AIC-S & $3.6 \mathrm{a}$ & $1.08 \mathrm{a}$ & $1.80 \mathrm{ab}$ \\
AIC & $3.2 \mathrm{a}$ & $0.98 \mathrm{a}$ & $1.46 \mathrm{a}$ \\
KIC & $3.6 \mathrm{a}$ & $1.17 \mathrm{a}$ & $1.65 \mathrm{ab}$ \\
\hline
\end{tabular}

* Medians in the same column followed by the same letter are not significantly different according to one-way repeated measures analysis of variance on ranks. 


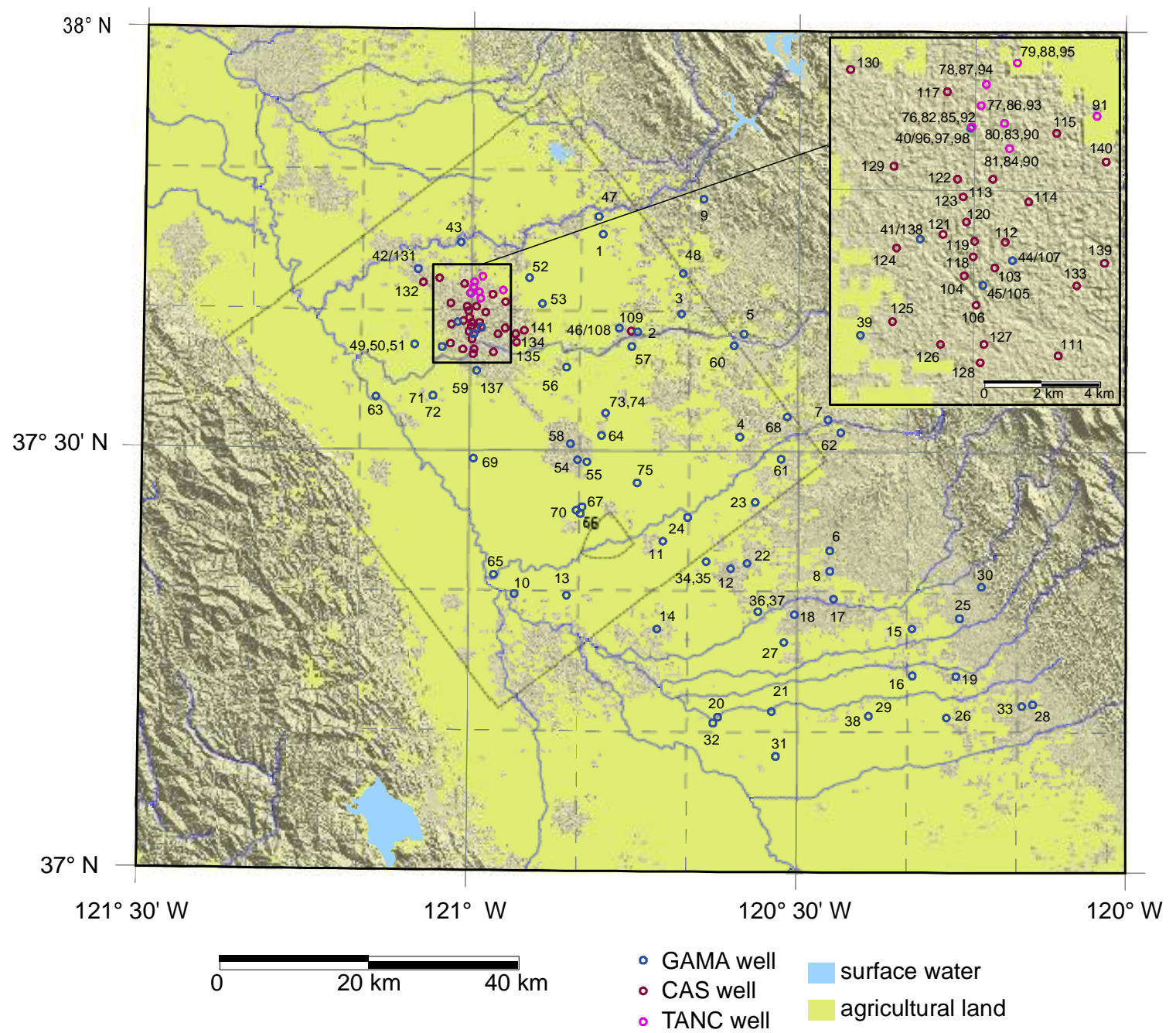

Figure 1. Site map showing shaded relief, major surface waters, boundaries of the regional model by Phillips et al. (2007) (dotted rectangle), the boundaries of the sub-model by Green et al. (2010, 2014) (small dotted polygon), and well locations. 
Well sample with multiple age tracers

(Section 2.2)

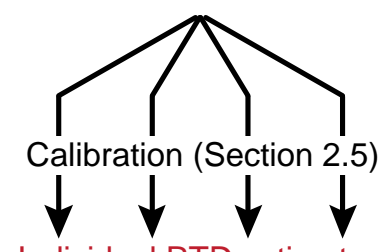

Individual RTD estimates

(Section 2.3)

EPM DEPM DM SDM

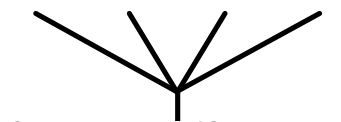

AIC averaging (Section 2.4)

$\downarrow$

Multimodel RTD (Section 2.4)

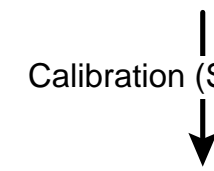

Estimates of $\mathrm{N}$ input function, $\mathrm{O}_{2}$ reduction rate, denitrification rate (Section 3)
Synthetic RTDs from

Green et al. (2014)

$\downarrow$

Multimodel method

comparison

(Section 2.4)

Figure 2. Schematic of methods, including stages of the estimation procedure (red text) and procedures (black text and arrows). 

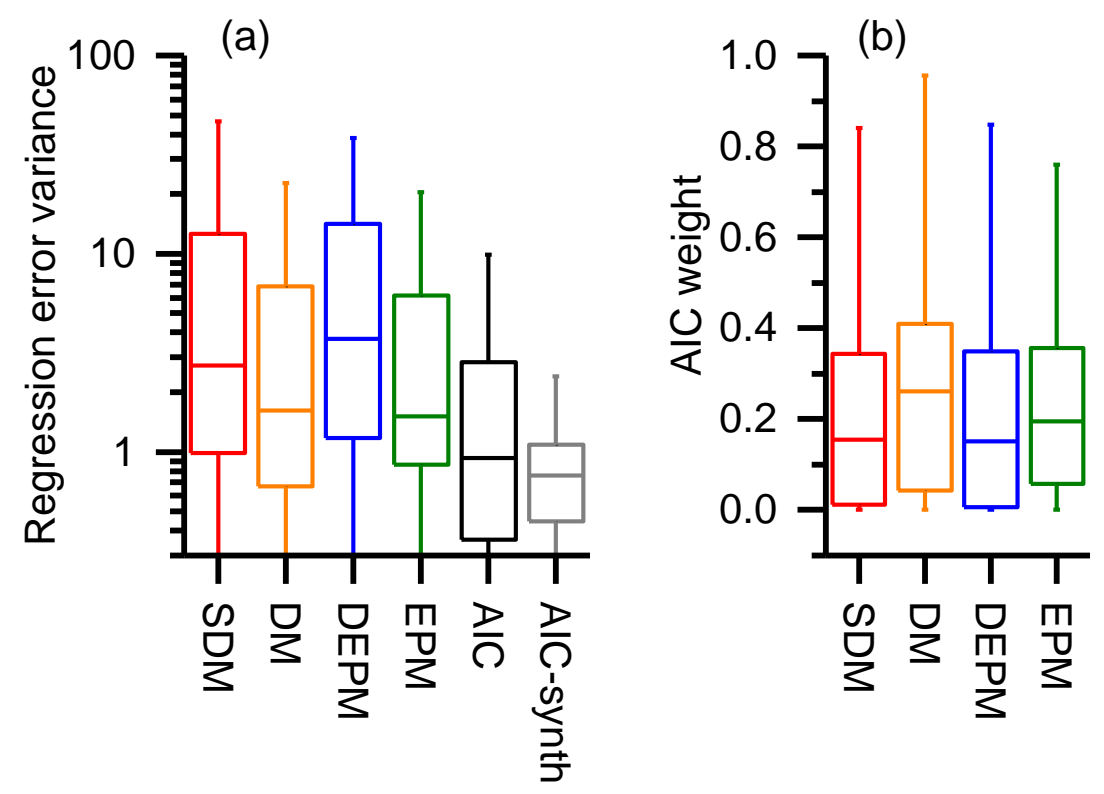

Figure 3. Distributions of (a) regression error variance and (b) Akaiki information criteria (AIC) weights for the scaled dispersion model (SDM), dispersion model (DM), dual exponential piston model (DEPM) and exponential piston model (EPM). Also shown on (a) are the AIC averages of the four individual models for the field data and for the synthetic (synth) data from Green et al. (2014). Boxes show the medians and interquartile range. Whiskers show the upper outer and lower outer fences. 
(a)

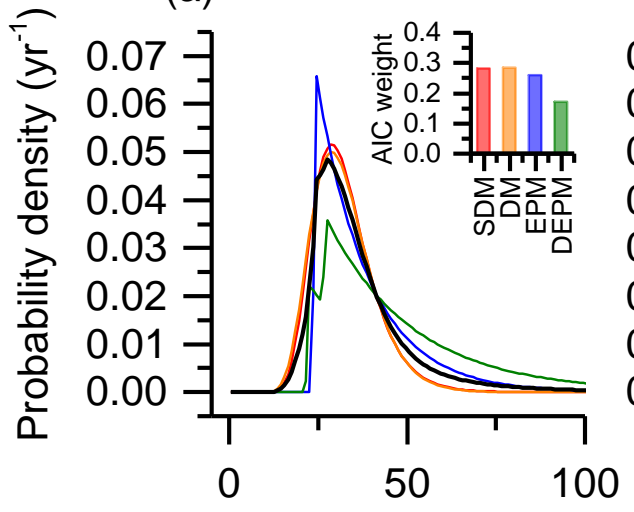

Residence time (yr) (b)

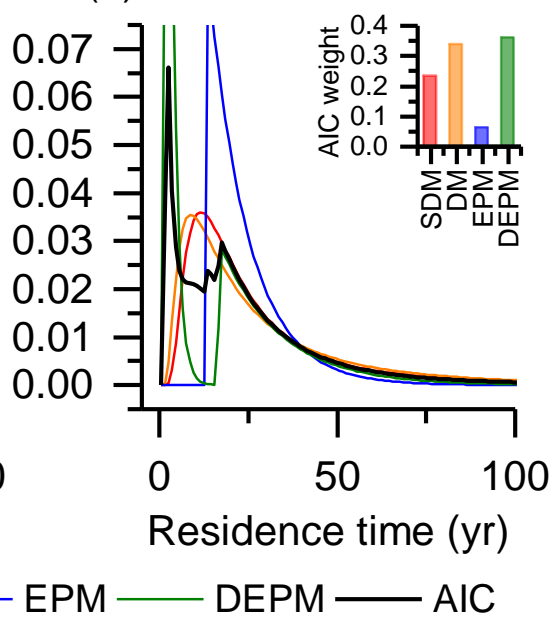

Figure 4. Examples of residence time distributions (RTDs) for (a) well sample 1 and (b) well sample 17. Lines show RTDs for the scaled dispersion model (SDM), dispersion model (DM), dual exponential piston model (DEPM), exponential piston model (EPM) and Akaiki Information Criteria (AIC) average of the four individual models. Inset column plots show AIC weights of the four individual RTD models. 


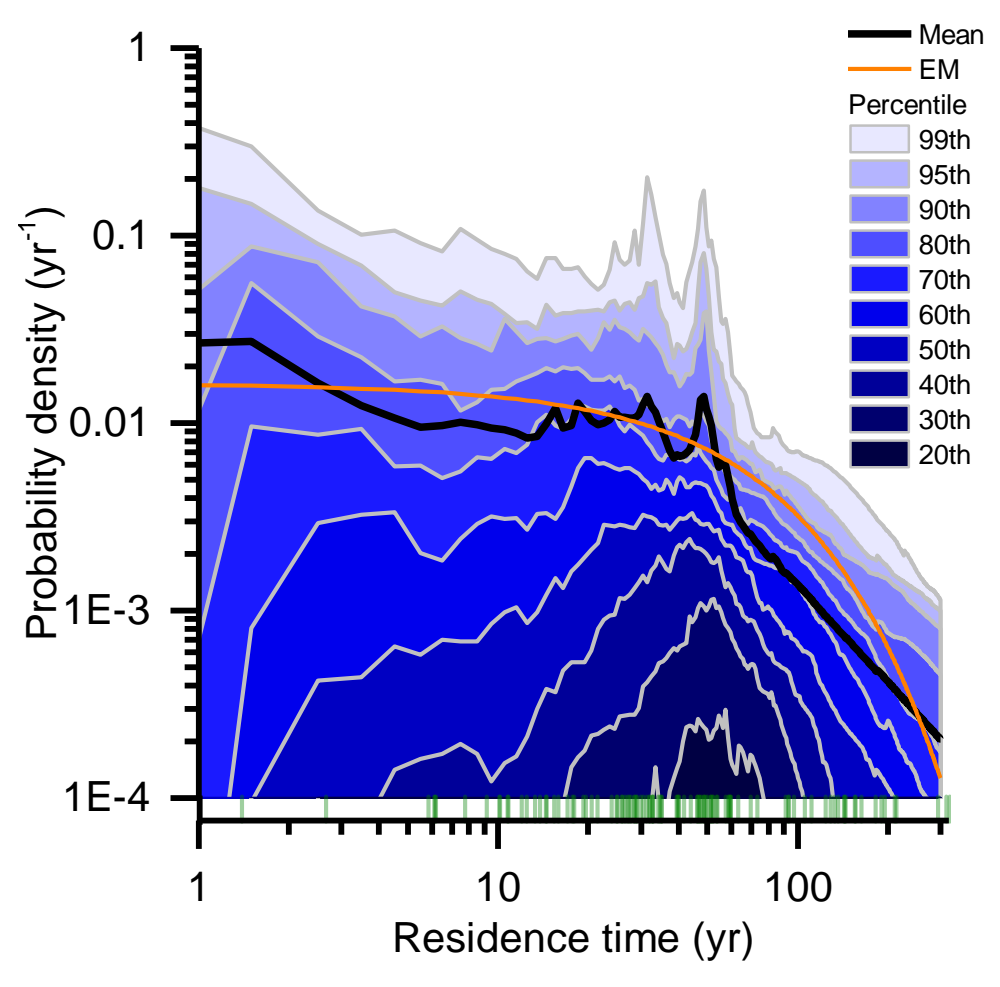

Figure 5. Summary of simulated residence time distributions (RTDs) for 129 well samples with three or more age-tracers. "EM" is the line for the best-fit exponential model fitted to the mean of the RTDs. Green vertical lines at bottom of plot are median ages of individual distributions. 


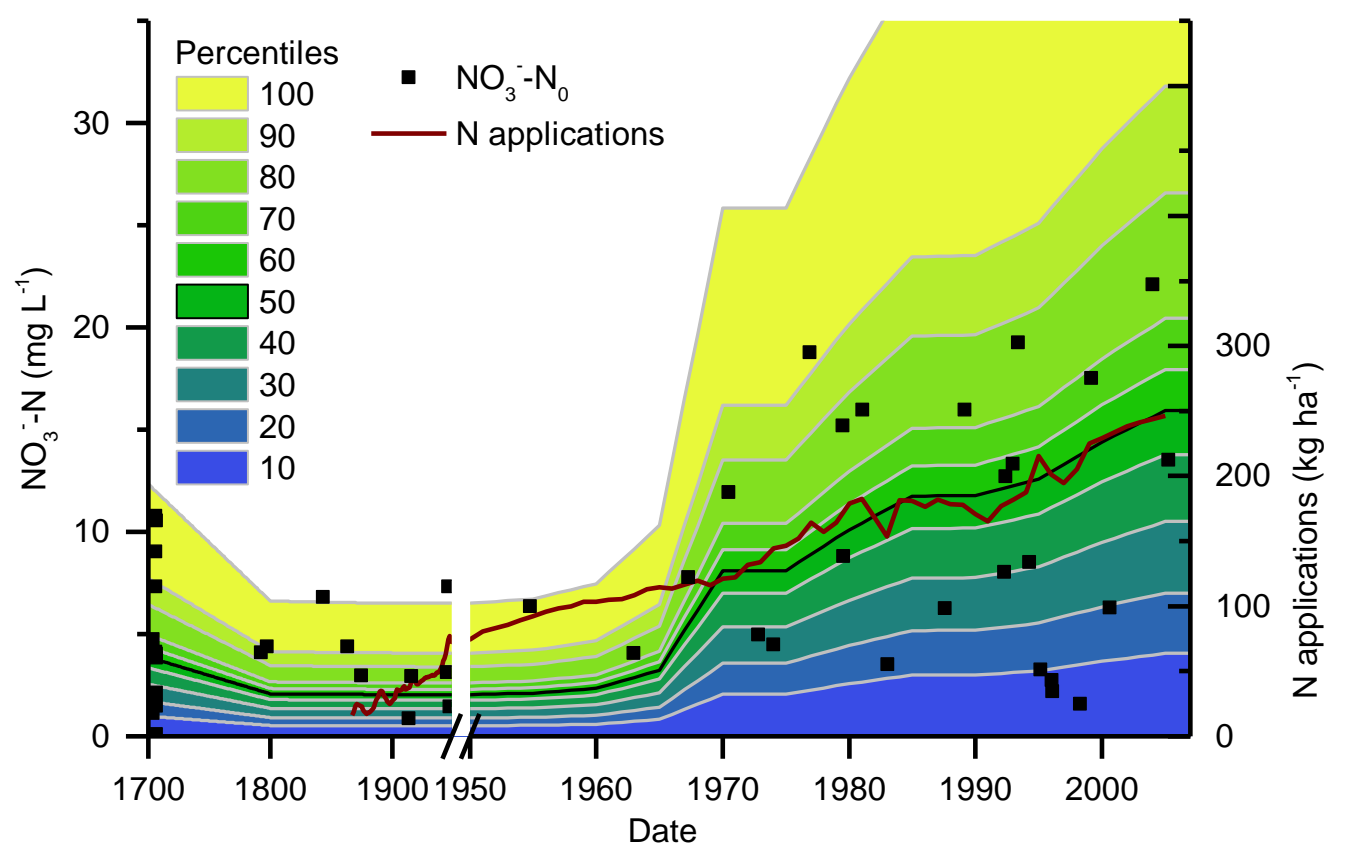

Figure 6. Estimates of $\mathrm{NO}_{3}{ }^{-}-\mathrm{N}$ input concentrations at the water table (left vertical axis) and aerial $\mathrm{N}$ application rates at land surface (right vertical axis). The color key gives the percentiles of estimated groundwater $\mathrm{NO}_{3}{ }^{-} \mathrm{N}$ input functions, with the median shown as a black line. Input functions of $\mathrm{NO}_{3}{ }^{-}-\mathrm{N}$ are linearly scaled versions of the shape function $C_{0, N}^{*}\left(t^{\prime}\right)$. Each point for $\mathrm{NO}_{3}{ }^{-}-\mathrm{N}_{0}$ shows the measured concentration of $\mathrm{NO}_{3}{ }^{-}-\mathrm{N}_{0}\left(\mathrm{NO}_{3}{ }^{-}\right.$plus $\mathrm{N}_{2}$ from denitrification) versus the estimated median residence time. Medians earlier than 1700 are shown at 1700. The $\mathrm{N}$-applications line shows the trend of fertilizer plus manure $\mathrm{N}$ in the study area (Green et al., 2014). 

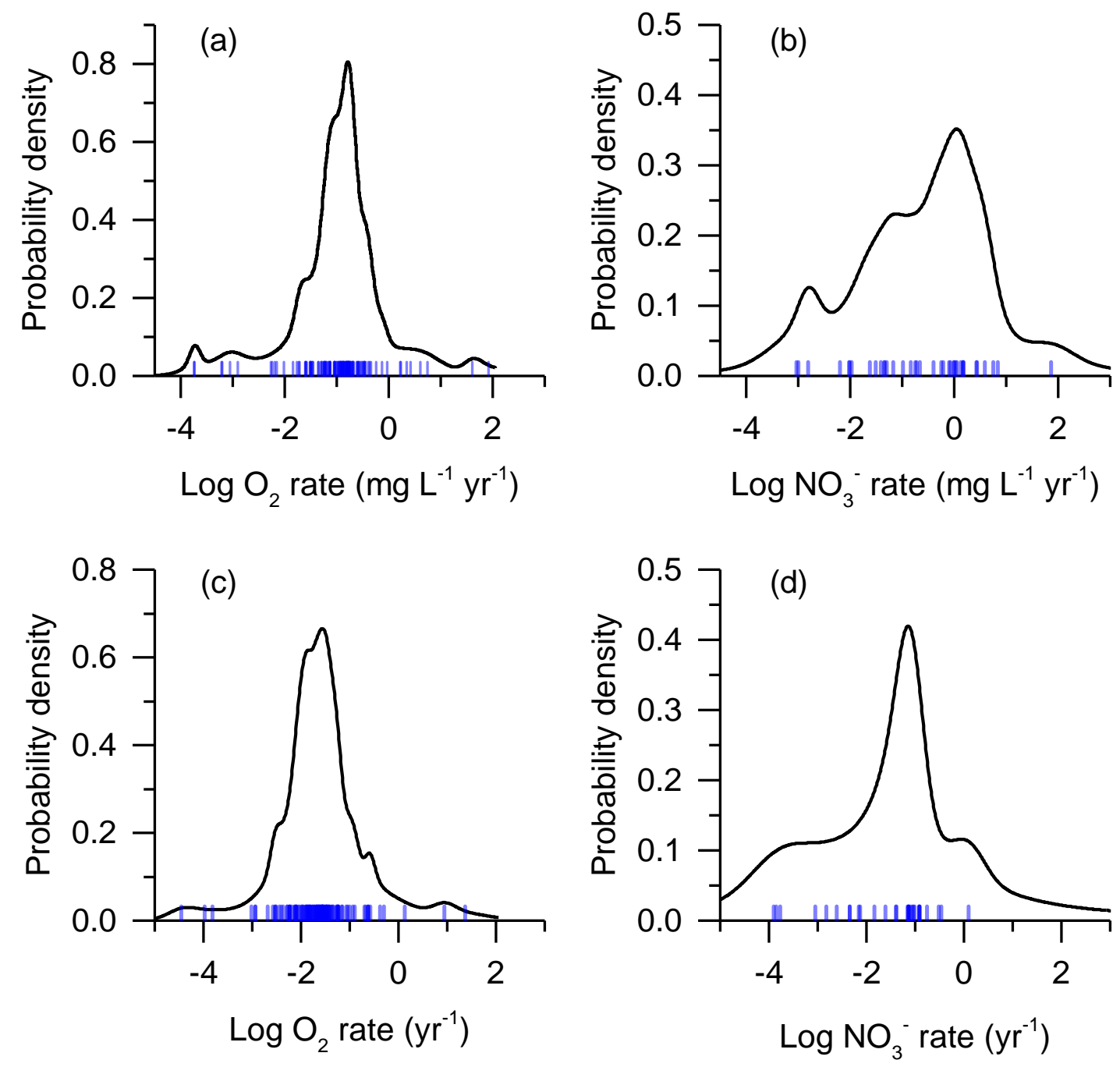

Figure 7. Estimated values (blue vertical lines) and probability density functions (black curves) of rate coefficients for (a) zero order $\mathrm{O}_{2}$ reduction, (b) zero order denitrification, (c) first order $\mathrm{O}_{2}$ reduction, and (d) first order denitrification. Each probability density function was calculated as the average of the probability distributions of the estimated values. 


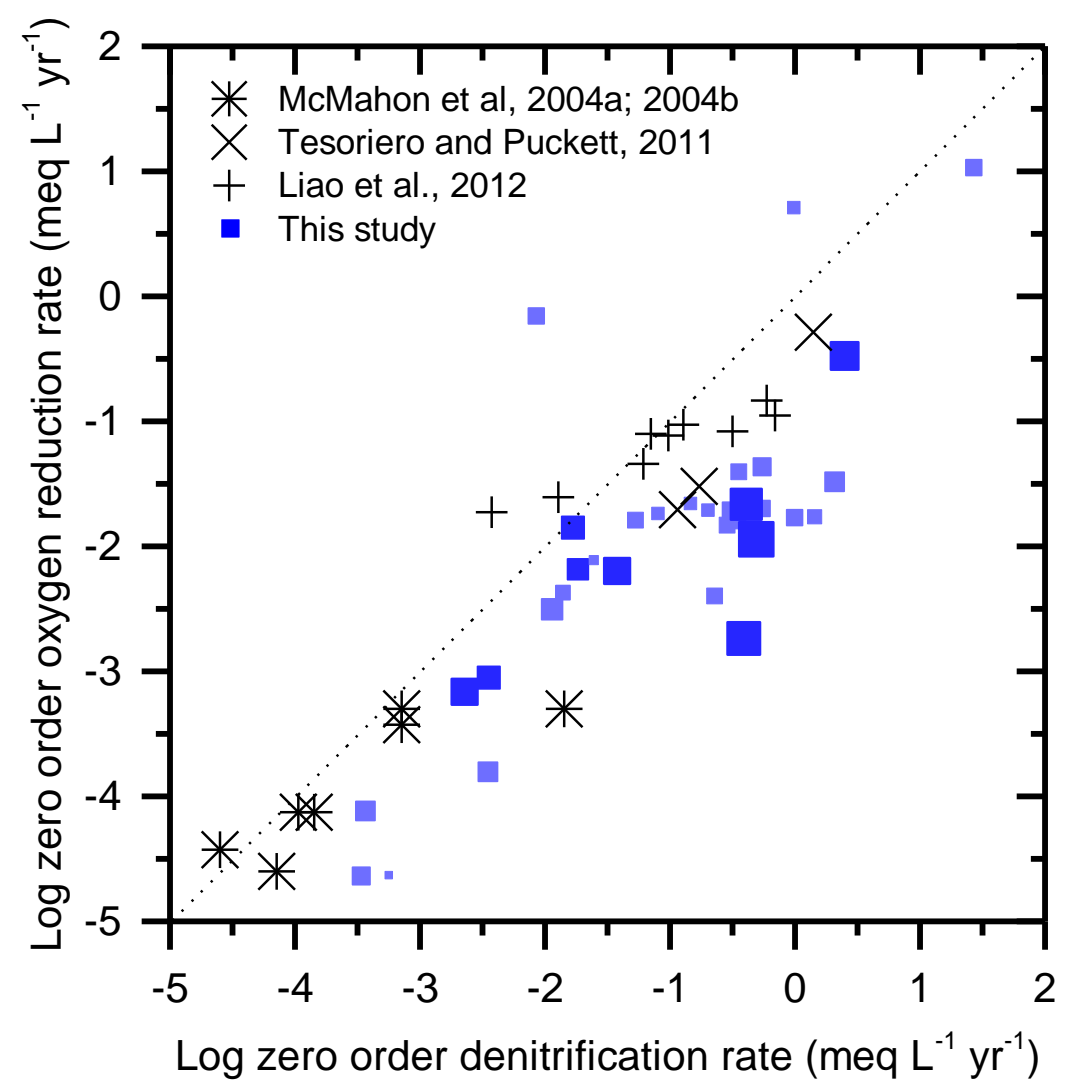

Figure 8. Comparison of zero-order reaction rate coefficients for reduction of $\mathrm{O}_{2}$ and denitrification of $\mathrm{NO}_{3}{ }^{-}$, with results from this study and from previous studies of site-by-site rate coefficient estimates. For each of the blue squares (results from this study) the size is inversely proportional to the uncertainty of the rates, as given by the geometric mean of the confidence intervals of the $\mathrm{O}_{2}$ reduction and denitrification rate coefficients. 


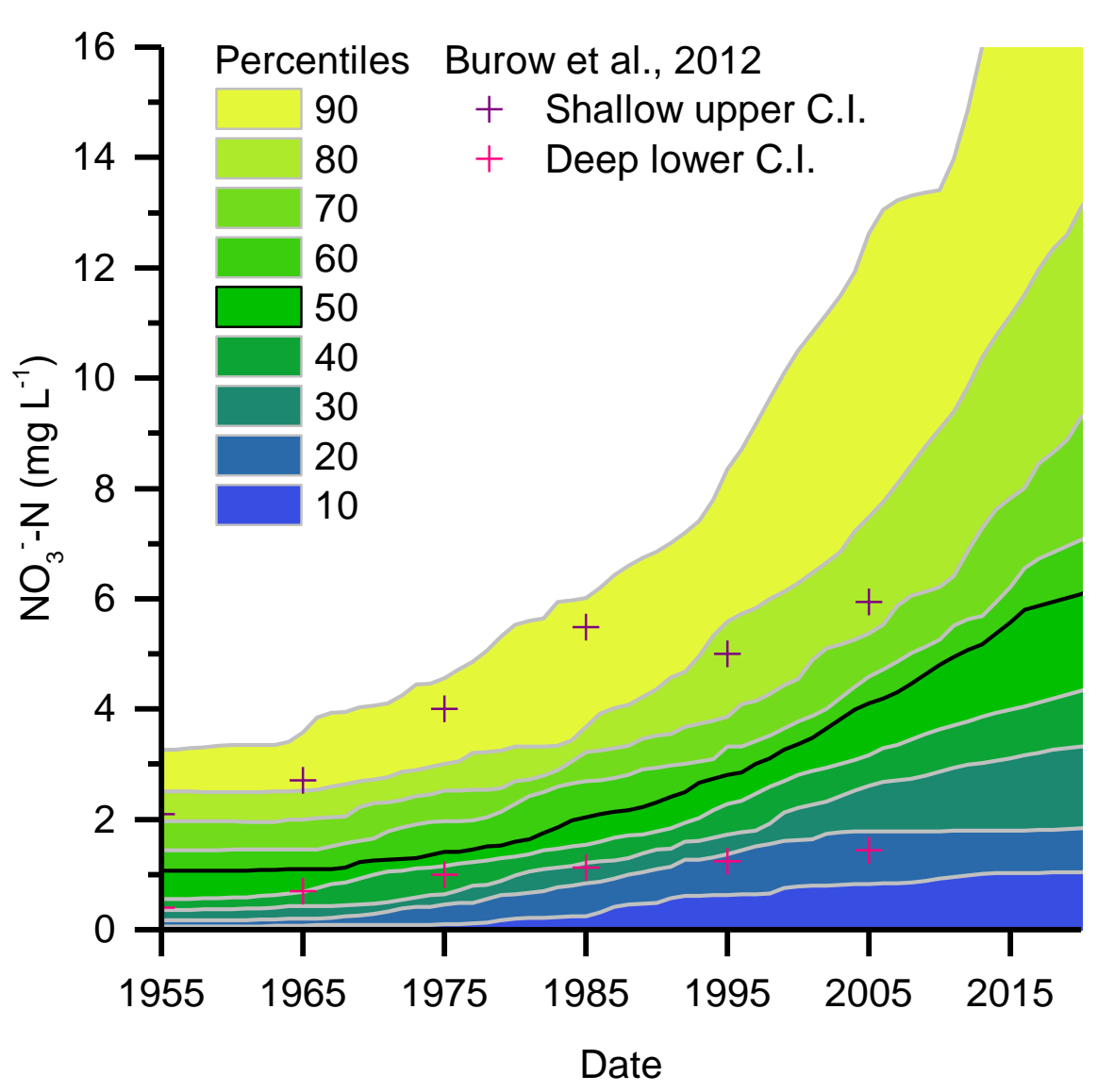

Figure 9. Modeled (solid lines and colors) and observed (points) $\mathrm{NO}_{3}{ }^{-} \mathrm{N}$ concentrations. Observed values are for the lower confidence interval of the median of $\mathrm{NO}_{3}{ }^{-} \mathrm{N}$ concentrations in deep wells (base of screen greater than $46 \mathrm{~m}$ below water table) and the upper confidence interval for shallow wells (less than $46 \mathrm{~m}$ ) as reported by Burow et al. (2012) for the eastern Central Valley alluvial fans. The solid black line shows the median of simulated values, and gray lines with colored filled areas show the percentiles. 